University of Rhode Island

DigitalCommons@URI

Open Access Master's Theses

1995

\title{
THIRD PARTY REIMBURSEMENT OF COMPOUNDED \\ PRESCRIPTIONS
}

Renuka Nair

University of Rhode Island

Follow this and additional works at: https://digitalcommons.uri.edu/theses

\section{Recommended Citation}

Nair, Renuka, "THIRD PARTY REIMBURSEMENT OF COMPOUNDED PRESCRIPTIONS" (1995). Open Access Master's Theses. Paper 271.

https://digitalcommons.uri.edu/theses/271

This Thesis is brought to you for free and open access by DigitalCommons@URI. It has been accepted for inclusion in Open Access Master's Theses by an authorized administrator of DigitalCommons@URI. For more information, please contact digitalcommons-group@uri.edu. 


\section{THIRD PARTY REIMBURSEMENT OF COMPOUNDED PRESCRIPTIONS}

BY

RENUKA NAIR

A THESIS SUBMITTED IN PARTIAL FULFILLMENT OF THE REQUIREMENTS FOR THE DEGREE OF MASTER OF SCIENCE 。

IN

PHARMACY ADMINISTRATION

THE UNIVERSITY OF RHODE ISLAND

1995 


\section{MASTER OF SCIENCE THESIS \\ OF \\ RENUKA NAIR}

\section{APPROVED:}

Thesis Committee

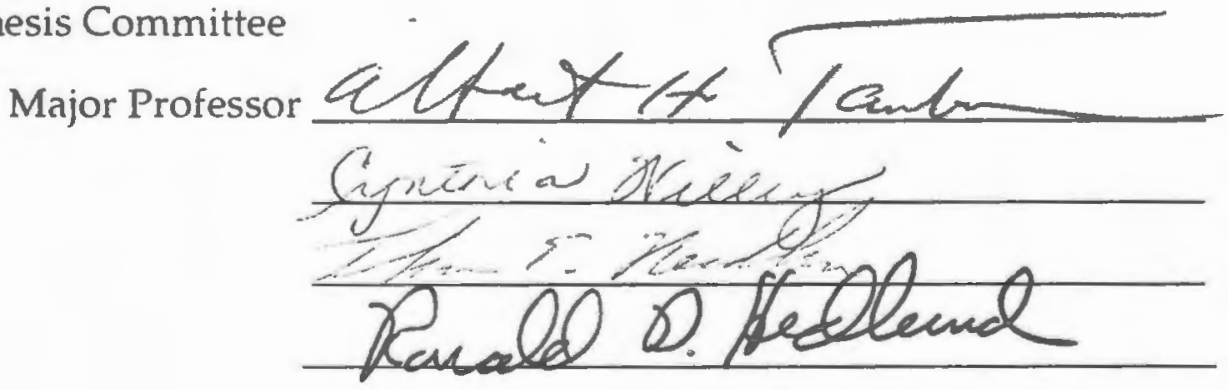

DEAN OF THE GRADUATE SCHOOL 


\begin{abstract}
A questionnaire was mailed to the third party providers $(n=313)$ registered with the National Council for Prescription Drug Programs (NCPDP), State Medicaid Programs and Blue Cross plans not listed with the NCPDP. The response rate was $41.5 \%$. The respondents were evaluated for their demographics (number of prescriptions processed, number of subscribers, number of drug benefit models and type of third party) and pre approval process (if they required the provider to obtain pre approval, process of pre approval, time required for giving pre approval and person responsible for obtaining the pre approval). Information was also gathered on drug utilization review conducted on compounded prescriptions and the reimbursement scheme for compounded prescriptions.
\end{abstract}

The results of the study revealed that the majority of third party providers do not perform any kind of drug utilization review on their compounded prescriptions. Also most of the third party providers in the study group did not require their provider to obtain pre approval nor did they have a preapproved list of compounded prescriptions. Moreover most of the respondents reimburse for drugs compounded for FDA unapproved uses.

It appears that there is a need for the third party to reevaluate their current reimbursement, review and coverage of compounded prescriptions. 


\section{ACKNOWLEDGMENT}

At the end of completion of my thesis there are several people to whom I would like to extend my gratitude, for without their assistance and assurance this study would have remained incomplete. First I would like to thank my major professor, Dr. Albert. Taubman for his constant guidance that was of tremendous value in every phase of this work. It was indeed my good fortune to have worked under such an excellent professor and nice person.

I would also like to thank Dr. Cynthia Willey and Dr. Thomas Needham, my committee members whose suggestions have helped me to enhance the quality of my thesis. Thanks to Dr. Panzica, the chairman of my thesis defense committee for his review of this document.

Special appreciation is extended to my colleagues Jaison and Denise and the faculty at the Department of Pharmacy Administration for making my stay at URI a memorable experience.

Finally thanks to my parents and sisters who inspite of being miles apart from me have been a constant source of love and inspiration. Thanks for always encouraging me to pursue my goals. 


\section{TABLE OF CONTENTS}

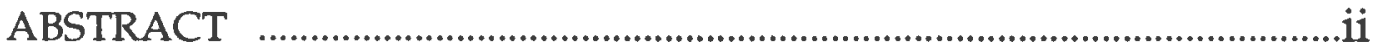

ACKNOWLEDGMENT ……....................................................................ii

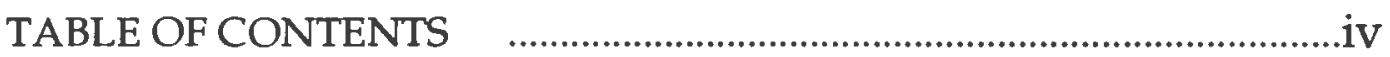

LIST OF TABLES _................................................................................

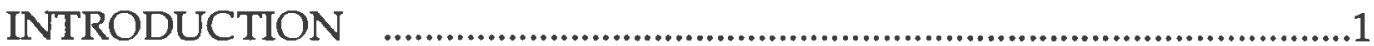

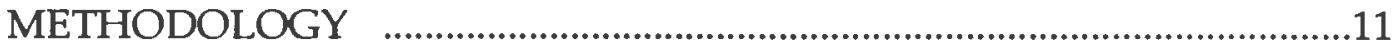

A. Measures

B. Procedure

C. Data Analysis

RESULTS

A. Characteristics of third party coverage of compounded prescriptions

1. Demographics of Third Party _......................17

2. Process of Pre approval ……………...............21

3. Drug Utilization Review ....................................23

4. Status of Compounded Prescriptions $\quad$...........25

5. Reimbursement Scheme …………………........28

B. Bivariate Analysis of Independent and Dependent Variables

1. Bivariate relationship between independent variables and if the third party require their provider to differentiate between compounded and non compounded prescriptions

2. Bivariate relationship between independent variables and if the third party have a preapproved list of prescriptions to be compounded

3. Bivariate relationship between independent variables and if the third party can identify when an FDA approved drug is compounded for unapproved uses. 
4. Bivariate relationship between independent variables and if the third party reimburse for FDA approved drugs compounded for unapproved uses. .34

5. Bivariate analysis between independent variables and if the third party require their provider to obtain pre approval before compounding the prescription..35

6. Bivariate relationship between independent variables and factors affecting the reimbursement of compounded prescriptions.

7. Bivariate analysis between independent variables and if the third party conduct drug utilization review on compounded prescriptions.

8. Bivariate relationship between independent variables and if the third party allow more than one active ingredient per compounded prescriptions. .38

9. Bivariate relation between independent variables and if the third party providers are aware of the growth of compounded prescriptions over the last two years...39

10. Bivariate relationship between the independent variables and if the third party require their participating pharmacies to provide compounding services.

11. Bivariate relationship between the independent variables and if the third party require their pharmacies to provide compounding services within a reasonable period of time.

DISCUSSION

CONCLUSIONS

LIST OF REFERENCES .50

APPENDIX .52

A. Data Collection Forms

B. SAS Programs

C. Frequencies of Data 


\section{LIST OF TABLES}

$\underline{\text { Table }}$

Page

1. Demographic characteristics of the third party providers

2. Process of pre approval

3. Drug Utilization Review ...................................................................24

4. Status of compounded prescriptions …………………………….......27

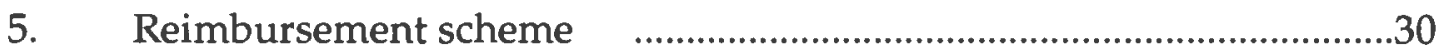

6. Summary of the bivariate association of the independent variables and if the third party require the provider differentiate between compounded and non compounded prescriptions

7. Summary of the bivariate association of the independent variables and the presence of a preappoved list

8. Summary of the bivariate association of the independent variables and if the third party can identify a drug compounded for FDA unapproved uses

9. Summary of the bivariate association of the independent variables and if the third party reimburse for drugs compounded for FDA unapproved uses

10. Summary of the bivariate association of the independent variables and the requirement for pre approval

11. Summary of the bivariate association of the independent variables and factors affecting the reimbursement of compounded prescriptions

12. Summary of the bivariate association of the independent variables and presence of drug utilization review

13. Summary of the bivariate association of the independent variables and if the third parties allow more than one active ingredient per compounded prescription 


\section{LIST OF TABLES (CONTINUED)}

13. Summary of the bivariate association and the growth of compounded prescriptions

14. Summary of the independent variables and the requirement

for all pharmacies to compound prescriptions

15. Summary of the bivariate association of the independent variables and the requirement for pharmacies to provide compounding services within a reasonable period of time 


\section{INTRODUCTION}

Compounding is a pharmacist's prerogative and has always been a part of pharmacy practice. The laws of some states include compounding in their definition of the practice of pharmacy 1 . The Latin recipe Secundum artum meant that the pharmacist would use his professional knowledge to compound drugs into a dosage form. The pharmacist was well aware of the physical and chemical properties and could make the dosage form providing a therapeutic effect.

Secundum artum empowered the pharmacist to combine drugs into a medication. Even today with the latest technological advances and growth of the pharmaceutical industry, almost $98 \%$ of the pharmacists compound drugs though on a relatively smaller scale 2 .

There are several reasons as to when and why a pharmacist may compound drugs.

1. Pharmacists compound drugs when they are not commercially available in the required strength or dosage form as required for optimum patient therapeutic activity. Usually drugs are available only in strengths and dosage forms that provide ease of administration and optimum therapeutic effect to the majority of patients. Thus the provider may prescribe and the pharmacist prepare and dispense drugs needed in limited strengths or alternate dosage forms and/or packaging. The problem becomes acute especially in geriatric and pediatric care. Many of the elderly have difficulty in swallowing and the provider often must tailor the dosage form to enhance patient compliance. In the case of pediatric medication many children are allergic to the dyes and preservatives found in commercially available products. Hence for this patients, the pharmacist can prepare the product free of such dyes or preservatives. 
2. Many times, for reasons of stability, a product should be prepared just before it is dispensed. In such cases, the pharmacist compounds small quantities of the prescription when the need arises.

3. Another form of compounding is in the field of radioactive substances. Nuclear pharmacists compound various radioactive substances for diagnosis, imaging and treatment of patients.

4. Sometimes physicians and pharmacists work together to make a product that meets a specific patient need. At times this has led to the development of a new dosage form that later became commercially available. Some examples are fentanyl lozenges, minoxidil lotion and nystatin lozenges 3 .

5. Home infusion therapy is the fastest growing segment of compounded prescriptions. The number of diagnoses that can be treated at home is increasing and so is the demand for home infusion therapy where compounding accounts for most of the product dispensed. The following table shows the market share of the various classes of drugs in home infusion market 4 .

Infusion treatment category Percent market share

Antibiotic 41

Total parenteral nutrition 23

Enteral nutrition

Chemotherapy

Other

Oncologists, gastroenterologists, internal medicine specialists, general practitioners, obstetricians/gynecologists and pediatricians are the most common prescribers of home infusion therapy 4 .

6. The emerging field of biotechnology is projected to provide tremendous opportunities for pharmacists to use their compounding skills. Many biotechnology drugs have a short half lifes, are expensive and require unique delivery systems. 
However today this very heritage of compounding is in the midst of a controversy. In the past few years there have been several cases where pharmacists were clearly manufacturing under the guise of compounding. In one such case, the FDA attempted to regulate a pharmacy that was involved in the manufacture of more than 300,000 dosage units of albuterol sulfate and other inhalation therapy drugs per month for 6,000 patients, most of which were shipped by interstate commerce ${ }^{5}$. Another firm was involved in the production of liquids in a 30 liter tank in a building that did not appear to be a pharmacy. This 'pharmacy location' had a shipping area, sterile area for compounding, mixing and filling area, a drug storage area, a billing area and two customer services offices. All the compounded products were shipped to customers by federal express or airborne express. There was absolutely no patient walk in with prescription dispensing service. The customers were pharmacies, medical supply firms and home health care facilities. This firm made its products by diluting brand name drugs and bulk drug products 5 . There were cases where the pharmacies diluted Proventil (a product of Schering laboratories), repackaged and marketed it as Proventil. Analysis of these samples found mislabeled or absent expiry dates and lot numbers, diluted concentrations of the antibacterial benzalkonium chloride and samples contaminated with pseudomonas 5 .

It was not only these issues concerned with the large scale manufacturing operations that drew the attention of FDA but also some of the practices and issues surrounding the traditional compounding of products. There were cases where the patients were affected by the medication compounded by the pharmacist. One such example of injury to the patients resulting from compounded products occurred in 1990 in Pittsburgh, PA. Several patients suffered from eye infection from the indomethacin eye drops that had been 
compounded by a pharmacist 6 . Two had to undergo surgical removal of the eye. In Nebraska some patients died after receiving microbially infected surgical solutions made by a hospital pharmacy 6 .

All such instances were viewed by the FDA from a public health perspective. Until recently the number of such cases concerned with compounding that came to the FDA notice were few and relatively less significant ${ }^{8}$. Also the practice of pharmacy was mainly left to the domain of the state boards of pharmacy. However lately there has been an increase in the number of pharmacies involved in the large scale manufacturing of drugs providing large quantities of adulterated, misbranded or unapproved drugs. In other words these pharmacies were clearly violating the Food, Drug and Cosmetic acts. These pharmacies were operating as a pharmaceutical companies except unlike the latter they did not conform to FDA regulation. In view of public health and safety and efficacy of products, the FDA issued an FDA Compliance Policy Guide 7132.16 (CPG) in March $1992^{9}$. The CPG discusses the factors that the agency will take into consideration while deciding whether a pharmacy has extended beyond the scope of traditional compounding and assumed the role of a manufacturer. According to these guidelines FDA action will take place in case the pharmacists resorted to the following activities.

1. Soliciting business (e.g. promoting, advertising, or using sales persons) to compound specific drug products, product classes, or therapeutic classes of drug products.

2. Compounding, regularly, or in inordinate amounts, drug products that are commercially available in the marketplace and that are essentially generic copies of commercially available, FDA approved products.

3. Receiving, storing, or using drug substances without first obtaining written assurance from the supplier that each lot of the drug substance has been made in an FDA approved facility. 
4. Receiving, storing or using drug components not guaranteed or otherwise determined to meet official compendia requirements.

5. Using commercial scale manufacturing or testing equipment for compounding drug products.

6. Compounding inordinate amounts of drugs in anticipation of receiving prescriptions in relation to the amounts of drugs compounded after receiving valid prescriptions.

7. Offering compounded drug products at wholesale to other state licensed persons or commercial entities for resale.

8. Distributing inordinate amounts of compounded products out of state.

9. Failing to operate in conformance with applicable state law regulating the practice of pharmacy.

The foregoing list of factors is not intended to be exhaustive and other factors may be appropriate for consideration in a particular case. CPG stated that FDA recognizes that pharmacists have traditionally compounded and manipulated reasonable quantities of drug upon receipt of a valid prescription (i.e., an oral or written order from a practitioner licensed by state law to administer or order the administration of the drug to an individual patient identified by the practitioner in the course of his or her professional practice) for an individually identified patient from a licensed practitioner. This traditional activity was not the subject of the CPG. According to the CPG, a pharmacist can compound in response to a valid prescription for an individual patient. Thus the CPG was only to differentiate between compounding and manufacturing. However the FDA officers at the local level sent warning letters to pharmacists for whom compounding constituted only around $2 \%$ of their total pharmacy sales 7 . These letters warned the pharmacists against FDA action in the event that they resorted to compounding. The reason was that any drug compounded in the pharmacy was a new drug and hence subject to NDA approval. This 
contradictory stand has created confusion among the pharmacists, pharmacist groups and other agencies as to whether compounding constitutes a violation of CPG.

As part of its effort to clear the confusion prevailing over compounding vs. manufacturing, the American Pharmaceutical Association (APhA) in consultation with FDA and other pharmacists has defined compounding and manufacturing.

Compounding has been defined as " the preparation, mixing, assembling, packaging or labeling of a drug or device (1) as the result of a practitioners prescription drug order or initiative based on the pharmacist / patient/ relationship in the course of professional practice or (2) for the purpose of, or as incident to research, teaching, or chemical analysis and not for sale or dispensing. Compounding also includes the preparation of drugs or devices in anticipation of prescription drug orders based on routine, regularly observed prescribing patterns 4 .

Manufacturing on the other hand is defined as the production, preparation, propagation, conversion or processing of a drug or device either directly or indirectly by extraction from substances of natural origin or independently by means of chemical or biological synthesis and includes any packaging or repackaging of the substances or labeling or relabeling of its container and the promotion and marketing of such drugs or devices. Manufacturing also includes the preparation and promotion of commercially available products from bulk compounds for resale by pharmacies, practitioners or other person 4 .

One of the largest groups of compounding pharmacists, Professional \& Patients for Customized Care (P2C2) filed a lawsuit against the federal government and many of its agencies to block the enforcement of CPG on the 
grounds that it violated the federal procedural law. The basic argument adopted by $\mathrm{P} 2 \mathrm{C} 2$ was that the CPG, adopted by the FDA as an internal guideline is actually a substantial change in federal policy that significantly have an impact on pharmacy practitioners, and that the policy should have been promulgated as a formal rule with advance notice to the public to comment ${ }^{5}$. However the US. District court ruled out that the FDA could continue to take actions against the pharmacies based on CPG since CPG did not significantly impact the traditional compounding of pharmacy profession. P2C2 has filed an appeal with the Fifth Circuit Court of appeal that will be decided sometime this year since the submission of this thesis the compounding controversy still exists.

All this confusion over compounding has raised questions regarding the third party coverage, review and reimbursement of compounded prescriptions. A detailed literature survey did not provide any information on the type of drug utilization review (DUR) performed on compounded prescriptions. In fact it is not even clear whether third party providers conduct DUR on compounded prescriptions. DUR can be performed on all the ingredients in the prescription or only on the active ingredient or the most costly ingredient. However the literature does not disclose any of this information.

Second the literature does not discuss any issues pertaining to preapproval. It remains unclear whether third party organization have a formulary of drugs or formula that can be compounded. No information is available as to whether providers are required to obtain pre approval before compounding any prescription. Also it remains unknown as to who is responsible for obtaining preapproval (physician or pharmacist or either), the mechanics of the preapproval process (form, phones, faxes) and the time period needed to obtain pre approval. 
Many times a physician in the course of his practice may prescribe a drug to be compounded for FDA unapproved uses. It is unclear as to whether these prescriptions will be reimbursed by the third party. Some or most of the compounded prescriptions may contain more than one active ingredient. As the number of active ingredients in the prescription increases the chances of adverse effects also increases. In the absence of any safety or efficacy studies, it remains unclear if the third party providers restrict the number of active ingredients per reimbursed compounded prescription.

Third, the literature does not discuss the type of reimbursement scheme adopted by the third party for compounded prescriptions. Only five of the State Medicaid programs specifically refer to compounded products in their reimbursement scheme. The District of Columbia reimburses compounded prescriptions on the basis of either allowable charges of all billable ingredients plus dispensing fee or the providers usual charge to the public ${ }^{10}$. The Medicaid program in Mississippi reimburses compounded prescriptions for topical use only if at least one legend drug (in therapeutic amounts) is included in the ingredients 10 . Mississippi also covers compounded oral medications when all ingredients are covered separately under their own drug codes in the formulary. The Medicaid program of Nebraska reimburses compounded prescriptions at the lesser value of product cost (Federal upper limit, State Maximum Allowable Cost or $\mathrm{EAC}^{1}$ ) plus an appropriate dispensing fee or at the usual and customary charge to the public ${ }^{10}$. The Medicaid program of Pennsylvania has defined a compounded prescription as one that is prepared at the time of dispensing and involves the weighing of at least one ingredient that must be a legend drug in therapeutic amount ${ }^{10}$. The Medicaid program of West Virginia defines

\footnotetext{
${ }^{1}$ EAC-Estimated Acquisition Cost is an estimation made by a third party, of the actual amount a pharmacy would pay a supplier for a given product.
} 
compounded prescriptions as any legend medicament requiring a combination of any two or more substances to exclude normal reconstitution operations 10 . There is no information regarding the reimbursement of compounded prescriptions under the remaining State Medicaid programs or by various private insurance companies.

Finally no data is available on the growth or decline of compounded prescriptions over the years. Almost all pharmacists occasionally compound prescriptions but the contribution of these prescriptions to their total prescription sales either in terms of volume or dollar amount remains unclear.

This study is designed to explore the issues of Drug Utilization Review, pre approval for compounding and the reimbursement scheme. The study focuses on the following areas:

\section{Current mode of reimbursement for compounded prescriptions}

This includes the formulas of the reimbursement scheme (e.g., EAC + dispensing fee), the number of models that reimburse compounded prescriptions and identify factors factors(e.g., dosage, time ) affecting the reimbursement scheme.

\section{Problems with the current coverage schemes}

To include documenting whether drug utilization review is performed on compounded prescriptions and whether the insurer reimburses for FDA approved drugs compounded for unapproved uses. In addition the study gathered information as to whether the insurer requires their participating pharmacies to provide compounding services and the time frame within which the services have to be provided. 


\section{Limitations on compounded prescriptions coverage}

To includes documenting the presence or absence of a formulary of drugs to be compounded, requirements for preapproval of compounding drugs, the type of preapproval process and the amount of time required for pre approval. 


\section{METHODS}

\section{MEASURES}

A draft questionnaire was initially developed. This consisted of 25 close ended questions pertaining to third party coverage, review and reimbursement of compounded prescriptions. The draft questionnaire was pretested, the panelist being graduate pharmacy students, faculty of the Division of Applied Pharmaceutical Sciences and third party administrators. The purpose for pretesting was to eliminate any discrepancies that might arise in the interpretation of these questions by the respondents. On the basis of the suggestions made by this group, a final questionnaire was developed.

The questionnaire was mailed to the third party providers, throughout the United States who comprised the target population. The list of their names and addresses was obtained from the National Council for Prescription Drug Programs(NCPDP), the State Medicaid programs and the Blue cross plans not listed in the NCPDP. The study took into consideration Health Insurer (Government, Not for Profit and For Profit), Health Maintenance Organizations, Mail Service Prescription Company and Pharmacy Benefit Management Company. The target population therefore composed of 313 third party providers.

The questionnaire (see appendix B ) was divided into four sections. The purpose of section one was to demographically describe the respondent. The respondents were asked to identify themselves as any of the following-for profit health insurance company, not for profit health insurance company, HMO, mail service prescription company, pharmacy benefit management company and Federal/State agency. Questions 2 and 3 sought to determine the number of subscribers enrolled and the total number of prescriptions processed during the 
calendar year 1993. Information was also gathered on the number of drug benefit models administered by the respondents under the capitation, fee for service and usual and customary reimbursement scheme. Hence section one attempts to describe the company in terms of the number of prescriptions processed, number of subscribers enrolled and the number of drug benefit models that in turn could be related to the reimbursement policy and coverage of compounded prescriptions.

The purpose of section two is three fold. First information was gathered regarding the number of models that reimbursed compounded prescriptions. Those respondents who did not reimburse compounded prescriptions or reimbursed only under some of their models were asked whether they intended to reimburse under all their models within the next two years. Questions were directed towards gaining more information on the reimbursement formula (e.g. EAC + dispensing fee) and if these formulas differ according to the dosage form or the time required for compounding.

Second the respondents were asked whether the company had any mechanism whereby they can identify when a drug is being compounded for FDA unapproved uses. Also an attempt was made to determine whether the respondents reimbursed FDA approved drugs compounded for unapproved uses.

The final part of this section focused on the pre approval process. The respondents were asked whether they have a pre approved list of prescriptions to be compounded and whether they require the provider to obtain pre approval before compounding. When pre approval is required, a series of questions followed trying to gather more information with respect to the person responsible for obtaining the pre approval (prescriber or pharmacist), the pre approval 
process (pre approval form, faxes, computer) and the number of hours required for pre approval.

Section three dealt with drug utilization review (DUR). The focus was to determine whether the third party conduct DUR and the type of DUR (retrospective, prospective or concurrent). Moreover the respondents were asked whether they conduct DUR only on the single most costly ingredient in the formula or on all the ingredients. Those respondents who do not currently conduct DUR on compounded prescriptions were asked as to whether they intended conducting it within the next two years.

The fourth and the final section of the questionnaire sought to determine the status of compounding under the present drug benefit programs. Questions were directed towards gaining details concerning the growth or decline of compounded prescriptions and the contribution of compounded prescriptions towards total prescription sales. Finally, the respondents were asked whether they require participating pharmacists to compound drugs and provide compounding services within a specified period of time.

\section{PROCEDURES}

A cover letter (Appendix A1) and self addressed, pre stamped envelope accompanied each questionnaire. The questionnaire was addressed to the person responsible for making corporate policies, usually the director of pharmacy programs. The cover letter explained in detail the intent of the study and requested the respondents to return the completed questionnaire within a specified period. To avoid bias and obtain accurate information the respondents were requested not to identify themselves. A month later, A second mailing with the same questionnaire and cover letter (Appendix A) was conductedand only those who had not replied were requested to return the questionnaire. 
Mailing of the questionnaire began on 12th December 1994. The deadline for the return was 15th January 1995. The follow up questionnaire was mailed on 23rd January and the deadline for the return was 20th February.

\section{DATA ANALYSIS}

The data was analyzed using SAS version 6.06 on the IBM Mainframe Computer System housed at the University of Rhode Island. The analysis was carried out to document the characteristics of reimbursement pertaining to compounded prescriptions using descriptive statistics. The main focus was on drug utilization review, pre approval, reimbursement scheme and the status of compounded prescriptions under the drug benefit program.

The Proc Freq was used to determine the frequencies of the variables. On the basis of the frequencies, the pertinent variables were selected for bivariate analysis. The independent variables were dichotomised at thier mid point, e.g number of subscribers was dichotomised as more than 100,000 and $0-100,000$. The independent variables included the type of third party, number of prescriptions processed, number of subscribers, number of drug benefit models and the percentage of compounded prescriptions in terms of total prescription volume. The dependent variables included the presence of DUR, number of ingredients on which DUR is conducted, factors (e.g. dosage, time) affecting the reimbursement formula, presence of a preapproved list of drugs to be compounded, whether the third party reimburses for FDA approved drugs compounded for unapproved uses, whether the third party require their provider to obtain pre approval before compounding prescriptions and the growth of compounded prescriptions (in terms of percentages) over the last two years.

Chi-square statistic was performed to measure the degree of association. Three levels of association was used: highly significant with p-values less than 
0.01 , significant with p-values of $0.01-0.10$ and marginally significant relationships had p-values of greater than 0.10 to 0.15 .

Prevalence odds ratio for the bivariate association between the independent variable and dependent variable was calculated using the formula (Kleinbaum 1982):

$\operatorname{Pr} \mathrm{OR}=$ (\# of exposed cases $)^{*}$ (\# of unexposed non cases)

(\# of exposed non cases)* (\# of unexposed cases)

A 95\% Confidence Interval for the odds ratio was calculated using the following formula-

$$
\text { 95\% CI }=\operatorname{Pr} \mathrm{OR}^{1} \pm(1.96 / X)
$$

where $\operatorname{Pr} O R$ is the prevalence odds ratio and $X$ is the square root of the chi square.

\section{Dichotomization of variables}

\section{Independent variables}

1. Type of third party $0=$ For profit health insurance company 1-Not for profit health insurance company

2. Number of prescriptons processed in the calendar year 1993

$0=$ More than 500,000 $1=0-500,000$

3. Number of subscribers enrolled

$0=$ More than 100,000 in the calendar year 1993 $1=0-100,000$

4. Percentage of compounded prescriptions $0=$ Greater than $1 \%$ in terms of total prescription volume $\quad 1=0-1 \%$

\section{Dependent variables}

1. Require the pharmacist to differentiate between $0=Y e s$ compounded and non compounded prescriptions $\quad 1=\mathrm{No}$ 
2. Presence of a preapproved list of prescriptions to be compounded

3. Able to identify when an FDA approved drug $0=$ Yes is compounded for unapproved uses

$1=$ No

4. Reimburse FDA approved drug compounded $0=$ Yes for unapproved uses $1=$ No

5. Require the provider to obtain preapproval before they can compound

$0=$ Yes

$1=$ No

6. Factors affecting the reimbursement of compounded prescriptions

$0=$ Dosage or time $1=$ None

7. Conduct drug utilization review on compounded prescriptions

$0=$ Yes

$1=$ No

8. Allow more than one active ingredient per compounded prescription

$0=$ Yes

$1=$ No

9. Growth of compounded prescriptions over the last two years

$0=$ Increased

$1=$ Decreased

10. Require all participating pharmacies to compound prescriptions

$0=$ Yes

$1=$ No

11. Require the pharmacies to provide compounding $0=$ Yes services within a reasonable period of time

$1=\mathrm{No}$ 


\section{RESULTS}

A total of 313 questionnaires (Appendix A ) were mailed to the third party providers registered with the National Council for Prescription Drug Programs (NCPDP), the state Medicaid programs and the Blue Cross plans. A total of 142 questionnaires were returned. Of these 6 were undeliverable. 5 were either not answered or incomplete. 1 was received after the cut off-date. Hence only 130 questionnaires could be used for the final analysis (41.53\%).

\section{A. CHARACTERISTICS OF THE THIRD PARTY COVERAGE, REVIEW AND REIMBURSEMENT OF COMPOUNDED PRESCRIPTIONS}

\section{Demographics of third party providers}

Table 1 provides the summary of the demographics of third party providers. A total of 130 third party providers responded to the survey. Pharmacy Benefit Management Companies dominated the study group representing $31.0 \%$ of the study group followed by the Federal/State agencies that accounted for $27.1 \% .11 .6 \%$ of the respondents were Health Maintenance Organizations while $4.7 \%$ constituted Mail Service Prescription Companies. For Profit Health Insurance Companies represented $19.4 \%$ of the study group and Not For Profit Health Insurance Companies the remaining 6.2\%.

About $63 \%$ of the third party providers processed more than $1,000,000$ prescriptions in the calendar year 1993. $16.5 \%$ of the respondents had $500,000-$ $1,000,000$ prescriptions while $9.4 \%$ processed between $0-50,000$ prescriptions during the same period. 50,000-100,000 and 100,000-500,000 prescriptions were processed by $3.1 \%$ and $7.9 \%$ of the third party providers in the study group respectively. 
$37.5 \%$ of the third party providers had $100,000-500,000$ subscribers enrolled in the calendar year 1993. More than 1,000,000 subscribers were enrolled by $22.7 \%$ of the respondents. Around 10,000-50,000 and 50,000-100,000 subscribers were enrolled by $5.5 \%$ and $11.7 \%$ of the third party providers in the study group respectively. $1.6 \%$ of the respondents had $0-5,000$ and another $1.6 \%$ had 5,000-10,000 subscribers enrolled in the calendar year 1993. The remaining $19.5 \%$ of the third party providers in the study group had 500,000-1,000,000 subscribers.

Majority of the respondents( $72.2 \%)$ had no models under the capitation system. $4.8 \%$ of the third party providers had one, $8.7 \%$ had two and $0.8 \%$ had three drug benefit models. $2.4 \%$ and $11.1 \%$ of the respondents revealed that they had four and more than four models respectively under the capitation system.

$14.3 \%$ of the respondents had no drug benefit plans under the fee for service system. One, two and three drug benefit models were available under this system in the case of $23.0 \%, 7.9 \%$ and $3.2 \%$ of the third party providers in the study group respectively. $4.0 \%$ of the respondents have four models and the remaining $47.6 \%$ had more than four models under the fee for service reimbursement scheme.

Under the usual and customary system, $46.8 \%$ had no drug benefit models. $13.5 \%$ had one, $9.5 \%$ had two, $1.6 \%$ had three and yet another $1.6 \%$ of the respondents revealed that they four models under the usual and customary reimbursement scheme. 


\section{Table 1. Demographic characteristics of third party}

Characteristics

$\%$ Total

( $n=130)$

\section{Type of third party}

For profit health insurance company

Not for profit health insurance company

Health Maintenance Organization

Mail Service Prescription Company

4.7

Pharmacy Benefit Management Company

Number of prescriptions processed in 1993

$0-50,000$

9.4

$50,000-100,000$

3.1

$100,000-500,000$

7.9

$500,000-1,000,000$

16.5

More than 1,000,000

Number of subscribers enrolled in 1993

$0-5,000$

$5,000-10,000$

1.6

$10,000-50,000$

5.5

$50,000-100,000$

11.7

$100,000-500,000$

37.5

500,000-1,000,000

19.5

More than $1,000,000$

Number of Drug Benefit Models

Capitation

None

72.2

One

Two

8.7

Three

0.8

Four

2.4

More than four

11.1 
Table 1....continued

\section{Characteristics}

\% Total

( $n=130)$

Fee for service

None

14.3

One

23.0

Two

7.9

Three

3.2

Four

4.0

More than four

47.6

Usual and customary

None

46.8

One

13.5

Two

9.5

Three

1.6

Four

1.6

More than four

27.0 


\section{PROCESS OF PREAPPROVAL}

A summary of the results of the pre approval process is presented in Table 2. Of the 130 respondents, $10.8 \%$ had a preapproved list of prescriptions to be compounded, however the majority $(89.2 \%)$ stated that they did not have a preapproved list.

$82.2 \%$ of the third parties in the study group did not require the provider to obtain pre approval before they could compound and receive reimbursement. $17.8 \%$ required the providers to obtain pre approval. Of those that required pre approval, $21.7 \%$ placed the responsibility on the prescriber while $47.8 \%$ required the pharmacist to obtain pre approval. $30.4 \%$ of the third party providers in the study group stated that they needed either the pharmacist or the prescriber to obtain the pre approval.

The process of pre approval also varied among the respondents who have the requirement of pre approval. $30.4 \%$ required the use of phone for obtaining pre approval. Pre approval form and computer were used by $8.7 \%$ and $4.3 \%$ of the respondents respectively. $8.7 \%$ did not restrict the process of pre approval. The providers could choose any of the processes. $4.3 \%$ each of the third parties required the provider to choose between form and fax or phone and fax or computer and phone or phone, fax and computer.

$43.5 \%$ of the respondents revealed that they gave approval immediately. About $34.8 \%$ stated that the process usually takes less than 24 hours while $21.7 \%$ replied that it took about 48 hours. 


\section{Table 2 Summary of the process of pre approval}

Pre approval

\% Total

$(n=130)$

Presence of a preapproved list of prescriptions

to be compounded

Yes

No

Require the provider to obtain pre approval

before compounding the prescription

Yes

17.8

No

Person responsible for obtaining pre approval

Prescriber

Pharmacist

Either pharmacist or prescriber

Process of pre approval

Form

computer

4.3

Phone

Any

8.7

Form or fax

4.3

Phone or fax

4.3

Phone or computer

Phone or fax or computer

4.3

Form or computer or phone

Form or phone or fax

Number of hours to obtain pre approval

Immediately

Within 24 hours

Within 48 hours

21.7

More than 48 hours

0.00 


\section{DRUG UTILIZATION REVIEW}

Table 3 shows the results of the Drug Utilization Review. $57.4 \%$ of the third party providers in the study group currently conduct drug utilization review on compounded prescriptions while the remaining $42.6 \%$ do not. Of those who do not perform DUR about $25 \%$ planned to do it in the next year, $8.9 \%$ in the next two years and $3.6 \%$ after two years. $57.1 \%$ of the third party who do not conduct DUR has no intention of conducting it even in future while $5.4 \%$ are still undecided as to whether they should perform DUR on compounded prescriptions.

$30.1 \%$ conduct retrospectively followed by $26.0 \%$ who conduct either of the three types. Concurrent review is performed by $9.6 \%$ and prospective by $5.5 \%$ of the respondents. About $8.2 \%$ of the respondents revealed that they conduct either prospective or retrospective studies while $1.4 \%$ stated that they perform either prospective or concurrent DUR.

$52.1 \%$ of the third party providers in the study group stated that they conduct DUR on all the ingredients in the prescription. However $41.1 \%$ of the respondents revealed that only the single costly ingredient in the prescription is taken into consideration for performing DUR. The remaining $6.8 \%$ of the respondents conduct DUR on either the costly ingredient or on all the ingredients.

With reference to the number of active ingredients in the compounded prescriptions about $94.5 \%$ did not place any restrictions on the number of active ingredients to be included in the compounded prescriptions. However $5.5 \%$ of the respondents did not allow the provider to compound more than one active ingredient per prescription. 


\section{Table 3 Process of Drug Utilization Review}

Drug Utilization Review

$\%$ Total

$(n=130)$

Conduct Drug Utilization Review on compounded prescriptions

Yes

No

Intend to conduct DUR on compounded prescriptions in future

Yes, within one year

Yes, within two years

8.9

Yes, after two years

3.6

No

Don't know

Type of Drug Utilization Review

Prospective

Concurrent

Retrospective

Concurrent \& Retrospective

Prospective \& Retrospective

8.2

Prospective \& Concurrent

1.4

All three types

Number of ingredients on which

DUR is performed

Only on the single costly ingredient

On all the ingredients

Either on costly or on all the ingredients

Allow more than one active ingredient per compounded prescription

Yes

No 


\section{Status of compounded prescriptions}

The status of compounded prescriptions under the drug benefit models is presented in table $4.46 .9 \%$ of the respondents were not aware if there was an increase or decrease in compounded prescriptions. $16.9 \%$ felt that it had remained the same. An increase of $0-5 \%$ was reported by $14.6 \%$ and $7.69 \%$ of the respondents stated that compounded prescriptions had increased by $6-10 \%$. Another $3.85 \%$ of the respondents was of the opinion that compounded prescriptions may have increased by $11-15 \%$ while an increase of $16-20 \%$ was felt by $1.54 \%$ of the respondents.

Of the third party providers who reported a decline in compounded prescriptions, $4.61 \%$ stated that there was a decline of $6-10 \%$ while a decline of 0 $5 \%$ was reported by $0.77 \%$ of the third party providers in the study group. $1.54 \%$ of the respondents revealed a decline of $16-20 \%$.

About $66.4 \%$ reported that compounded prescriptions accounted for less than $1 \%$ of their total prescription volume. $24 \%$ of the respondents revealed that it made up $1-5 \%$ of their total prescription volume. Compounded prescriptions represented about $6-10 \%$ of the prescription volume in $1.6 \%$ of the respondents drug benefit programs. $8 \%$ of the third party providers in the study were not aware of the contribution of compounded prescriptions to their total prescription volume.

$34.6 \%$ of the respondents required their participating pharmacies to compound prescriptions under all their drug benefit models while $1.5 \%$ required it only under some models. $63.8 \%$ did not place any emphasis on providing compounding services by their pharmacies.

$21.5 \%$ of the third party providers in the study allowed a time limit on 24 hours to their pharmacies for providing compounding services. A time period of 
more than 24 hours was acceptable to $3.8 \%$ of the respondents. $74.6 \%$ of the third party providers in the study group revealed that they did not place any time restrictions on their pharmacies for providing compounding services. 


\section{Table 4 Status of compounded prescriptions}

Variable

$\%$ Total

( $n=130)$

Percentage of compounded prescriptions

in terms of total prescription volume

Less than $1 \%$

66.4

$1-5 \%$

24.0

$6-10 \%$

1.6

Don't know

8.0

Growth in compounded prescriptions

Increased by $0-5 \%$

Increased by $6-10 \%$

7.69

Increased by $11-15 \%$

3.85

Increased by $16-20 \%$

1.54

Increased but don't

know by how much

1.54

Decreased by $0-5 \%$

0.77

Decreased by $6-10 \%$

4.61

Decreased by $16-20 \%$

1.54

Remained the same

Don't know

46.92

Require all participating pharmacies to provide compounding services

Yes, in all the models

Yes, in some of the models

1.5

No

63.8

Require the pharmacies to provide services within a reasonable period of time

Yes, within 24 hours

Yes, more than 24 hours

3.8

No

74.6 


\section{Reimbursement scheme}

A summary of the reimbursement scheme is given in table 5 .

All the third party providers in the study reimbursed compounded prescriptions under their capitation scheme. $88 \%$ of them reimbursed under all the models while $11.43 \%$ reimbursed under some of the models. Of the respondents who offered fee for service scheme, $94.39 \%$ reimbursed compounded prescriptions under all the models while $4.67 \%$ reimbursed under some of their models. The remaining $0.93 \%$ did not reimburse compounded prescriptions under any of their fee for service models. Regarding the third party providers who had the usual and customary models, $86.57 \%$ reimbursed under all their models while $7.46 \%$ reimbursed only under some of their models. $6.89 \%$ of the respondents did not reimburse under any of their usual and customary models.

The majority of the respondents $82.2 \%$ required their provider to differentiate between compounded and non compounded prescriptions for reimbursement. The remaining $17.8 \%$ of the third party providers in the study revealed that they did not require the pharmacist to specify the type of prescription.

$31.5 \%$ of the respondents stated that they were not able to identify when an FDA approved drug is compounded for unapproved uses. $68.5 \%$ of the third party providers could determine when an FDA approved drug was compounded for unapproved uses.

Regarding the reimbursement for FDA unapproved uses, $50.4 \%$ of the respondents stated that they reimburse an FDA approved drug compounded for unapproved uses. $49.6 \%$ revealed that they did not reimburse for the same.

Dosage of the compounded prescription was taken into consideration for reimbursement by $4.0 \%$ of the respondents. $8.0 \%$ of the third party in the study 
group took time required for compounding into account while $10.4 \%$ took both time and dosage into account while reimbursing compounded prescriptions. $77.6 \%$ of the third party providers revealed that none of these factors affected their reimbursement formula. 


\section{Table 5 Summary of the reimbursement scheme}

Reimbursement scheme

$\%$ Total

( $n=130)$

Number of models that reimburse compounded prescriptions

\section{Capitation}

All

Some

None

Fee for service

All

Some

4.67

None

Usual and customary

All

Some

7.46

None

6.89

Require the provider to differentiate between compounded and non compounded prescriptions

Yes

82.2

No

Able to identify when an FDA approved drug is compounded for unapproved uses

Yes

No

Reimburse FDA approved drugs compounded for unapproved uses

Yes

No

Factors affecting the reimbursement scheme

Dosage

Time required for compounding

Both dosage and time

5.6

None 
The Bivariate Relationship Between the Independent Variables and If the Third Party Require the Provider to Differentiate Between Compounded and Non Compounded Prescriptions for Reimbursement

The analysis for the relationship between the third party requirement to differentiate between compounded and non compounded prescriptions and the independent variables are shown in table 6. No statistically significant association was found among any of the variables. The chi-square value ranged from 0.002 (number of drug benefit models) to 1.411 (type of third party).

Table 6 Summary of the bivariate association of the independent variables and if the third party requires their providers to differentiate between compounded and non compounded prescriptions for reimbursement.

Variable

Type of third party

(For profit vs. Not For Profit)

Number of prescriptions

$(>500,000$ vs. $<500,000)$

Number of subscribers

$(>100,000$ vs. $<100,000)$

Number of drug benefit models

$(>8$ vs. $\leq 8$ )

Percentage of compounded prescriptions in terms of total prescription dollars

$(\geq 1$ vs. $<1)$
$\underline{X}^{2}$

1.411

0.179

0.672

0.074

0.785

0.002

0.965

0.405

0.525

p-value

0.235 
Bivariate Association Between The Independent Variables and if the Third Party have a Preapproved List of Prescriptions to be Compounded

The analysis for the bivariate association for the presence of a preapproved list of prescriptions to be compounded is presented in table 7 . The variable, number of drug benefit models and type of third party were the only statistically significant variables. The prevalence odds ratio for this variables were 3.17 and 0.35 respectively. One of the variables, percentage of compounded prescriptions had cells too small to count, i.e., there was only one respondent in a particular cell. The remaining variables had Chi-squares 0.629 (number of prescriptions) and 0.068 (number of subscribers)

Table 7 Summary of the bivariate association of the independent variables and presence of a preapproved list of prescriptions to be compounded

Variable

Type of third party

(For Profit vs. Not For Profit)

Number of prescriptions $(>500,000$ vs. $<500,000)$

Number of subscribers $(>100,000$ vs. $<100,000)$

Number of drug benefit models (>8 vs. $\leq 8$ )

Percentage of compounded prescriptions in terms of total prescription dollars $(\geq 1$ vs. $<1)$
$\underline{X}^{2} \quad \underline{\text { p-value }} \quad \underline{\operatorname{PrOR}} \quad \underline{95 \% \mathrm{CI}}$

$0.069 \quad 0.35$

0.629

0.428

0.068

0.795

4.100

0.043

$3.17 \quad 1.037,9.68$

CELLS TOO SMALL TO COUNT 
The Bivariate Relationship Between the Independent Variables and if the Third Party can Identify when an FDA Approved Drug is Compounded for Unapproved Uses

The variables, number of prescriptions and number of subscribers did not reveal any statistically significant association with Chi-square values of 0.011 and 1.007 respectively. The variables, number of drug benefit models $\left(X^{2}=2.273\right.$, $\mathrm{p}=0.132)$ and the type of third party $\left(\mathrm{X}^{2}=2.294, \mathrm{p}=0.13\right)$ showed a significant association with prevalence odds ratio of 1.78 and 0.56 respectively. (Table 8 )

Table 8 Summary of the bivariate association between the independent variables and if the third party can identify when an FDA approved drug is compounded for unapproved uses

Variable

Type of third party

(For Profit vs. Not For Profit)

Number of prescriptions

$(>500,000$ vs. $<500,000)$

Number of subscribers

$(>100,000$ vs. $<100,000)$

Number of drug benefit models

(>8 vs. $\leq 8$ )

$\%$ of compounded prescriptions in terms of total prescription dollars $(\geq 1$ vs. $<1$ )
$X^{2} \quad$ p-value $\quad \underline{\operatorname{PrOR}} \quad 95 \% \mathrm{CI}$

$\begin{array}{llll}2.294 & 0.130 & 0.56 & 0.265,1.183\end{array}$

$0.011 \quad 0.916$

$1.007 \quad 0.316$

$\begin{array}{llll}2.273 & 0.132 & 1.78 & 0.843,3.766\end{array}$

$0.192 \quad 0.662$ 
The Bivariate Association Between the Independent Variables and if the Third Party Reimburse for FDA Approved Drug Compounded for Unapproved Uses.

The analysis for the bivariate association between the independent variables and reimbursement for FDA approved drug compounded for unapproved uses as the dependent variable is presented in Table 9 . None of the variables showed any statistically significant association. The Chi-square value ranged from 0.034 (number of prescriptions) to 1.716 (percentage of compounded prescriptions).

Table 9 Summary of the bivariate association between the independent variables and if the third party reimburse for FDA approved drugs compounded for unapproved uses

Variable

Type of third party

(For Profit vs. Not For Profit)

Number of prescriptions

$(>500,000$ vs. $<500,000)$

Number of subscribers

$(>100,000$ vs. $<100,000)$

Number of drug benefit models (>8 vs. $\leq 8$ )

Percentage of compounded prescriptions in terms of total prescription dollars $(\geq 1$ vs. $<1)$ $\underline{x}^{2}$

p-value

0.626

0.034

1.556

0.949

1.716
0.190

0.429

0.212

0.330

\author{
(3)
}


The Bivariate Association Between the Independent Variables and if the Third Party Require the Provider to obtain Pre approval before they can compound and receive reimbursement

The analysis for the association between whether the third party require their providers to obtain pre approval before they can compound and receive reimbursement and the independent variables is found in Table 10 . The variables, number of prescriptions processed in the calendar year $1993\left(X^{2}=4.539\right.$, $p=0.033)$ number of subscribers enrolled during the same period $\left(X^{2}=2.087\right.$, $\mathrm{p}=0.149)$ and the type of third party $\left(\mathrm{X}^{2}=2.374, \mathrm{p}=0.098\right)$ showed statistically significant association. The prevalence odds ratio associated with these variables were $0.342,0.473$ and 0.466 respectively.

The summary of the analysis is presented in table 10 .

Table 10 Summary of the bivariate association between independent variables and if the third party require the provider to obtain pre approval

Variable

$\underline{X}^{2} \quad \underline{p-y a l u e} \quad \underline{\operatorname{PrOR}}$

$95 \%$ CI

Type of third party

$\begin{array}{llll}2.734 & 0.098 & 0.466 & 0.188,1.15\end{array}$

(For Profit vs. Not For Profit)

Number of prescriptions

4.539

0.033

0.342

$0.12,0.918$

$(>500,000$ vs. $<500,000)$

Number of subscribers

0.149

0.473

$0.17,1.305$

$(>100,000$ vs. $<100,000)$

$0.261 \quad 0.610$

Number of
(>8 vs. $\leq 8)$

$\%$ of compounded prescriptions in

1.620

0.203

terms of total prescription dollars

$(\geq 1$ vs. $<1)$ 
The Bivariate Association Between the Independent Variables and if the Reimbursement Scheme differ based On Dosage. Time Required For Compounding or other factors.

The analysis for the relationship between the factors affecting the reimbursement formula and the independent variables is presented in table 11. The analysis did not reveal any statistically significant variables. The Chi-square value was 1.895 for the variable, number of prescriptions, 1.32 for the number of subscribers and 0.188 for the number of drug benefit models. The variable percentage of compounded prescriptions had cells too small to count.

Table 11 Summary of the bivariate association between independent variables and factors affecting the reimbursement scheme

Variable

Type of third party

(For Profit vs. Not For Profit)

Number of prescriptions

$(>500,000$ vs. $<500,000)$

Number of subscribers

$(>100,000$ vs. $<100,000)$

Number of drug benefit models $(>8$ vs. $\leq 8)$

Percentage of compounded prescriptions in terms of total prescription dollars $(\geq 1$ vs. $<1$ )
0.665

0.169 p-value

0.773

CELLS TOO SMALL TO COUNT 
The Bivariate Association Between the Independent Variables and if the Third Party Conduct Drug Utilization Review on Compounded Prescriptions

The analysis for the bivariate association between the presence/absence of DUR and the independent variables revealed statistically significant association between the type of third party $\left(X^{2}=4.070, p=0.044\right)$ and the dependent variable. The Chi-square value for the variables ranged from 0.076 ( percentage of compounded prescriptions) to 1.939 ( number of prescriptions). The summary of the analysis is shown in table 12.

Table 12 Summary of the bivariate association between the independent variables and if the third party conduct Drug Utilization Review

Variables

Type of third party

(For Profit vs. Not For Profit)

Number of prescriptions

$(>500,000$ vs. $<500,000)$

Number of subscribers

$(>100,000$ vs. $<100,000)$

Number of drug benefit models (>8 vs. $\leq 8$ )

Percentage of compounded prescriptions in terms of total prescription dollars $(\geq 1 \%$ vs. $<1 \%$ )
$\underline{X}^{2} \quad$ p-value $\quad \underline{\operatorname{PrOR}} \quad 95 \% \mathrm{CI}$

$\begin{array}{llll}4.070 & 0.044 & 0.4722 & 0.97,2.27\end{array}$

$1.939 \quad 0.164$

$0.261 \quad 0.610$

$0.712 \quad 0.399$

$0.076 \quad 0.782$ 
The Bivariate Association Between the Independent Variables and if the Third Party Allow More than one Active Ingredient Per Compounded Prescription

The analysis for the association between the number of ingredients per compounded prescription as the dependent variable and the independent variables is given in table 13. No statistically significant association was found for the variables number of prescriptions $\left(X^{2}=0.189\right)$ and the number of subscribers $\left(X^{2}=0.181\right)$. The variable type of third party had an odds ratio of 3.8. The variable number of drug benefit models also showed significant association with Chi-square as 3.417 and a p-value of 0.065 . The prevalence odds ratio for this variable was 0.228 . The variable percentage of compounded prescriptions had cells too small to count.

Table 13 Summary of the bivariate association between the independent variables and if the third party allow more than one active ingredient per compounded prescription

Variables

Type of third party

(For Profit vs. Not For Profit)

Number of prescriptions

$(>500,000$ vs. $<500,000)$

Number of subscribers

$(>100,000$ vs. $<100,000)$

Number of drug benefit models $(>8$ vs. $\leq 8$ )

$\%$ of compounded prescriptions in terms of total prescription dollars $(\geq 1$ vs. $<1)$
$\underline{X}^{2} \quad$ p-value $\underline{\operatorname{PrOR} \quad 95 \% \mathrm{CI}}$

2.73

0.099

3.8

$0.78,18.5$

0.189

0.663

0.181

0.671

3.417

0.065

0.228

$0.047,1.09$

CELLS TOO SMALL TO COUNT 
The Bivariate Association Between the Independent Variables and the Third Party Perception about the Growth of Compounded Prescriptions Over the Last Two Years

The analysis revealed statistically significant relationship between the dependent variable and the number of drug benefit models $\left(X^{2}=5.745, p-\right.$ value $=0.017$ ). The prevalence odds ratio was 2.553 . The other three variables had Chi-square values ranging from 0.007 (type of third party) 4.076 (number of prescriptions).

Table 14 Summary of the bivariate association between the independent variables and their knowledge about the growth of compounded prescriptions over the last two years

Variable

$$
\underline{X}^{2}
$$

p-value $\underline{\operatorname{Pr} O R}$

$95 \%$ CI

Type of third party

0.007

0.933

(For Profit vs. Not For Profit)

Number of prescriptions

$(>500,000$ vs. $<500,000)$

Number of subscribers

$(>100,000$ vs. $<100,000)$

Number of drug benefit models

5.745

0.017

2.553

$1.185,5.495$

$(>8$ vs. $\leq 8$ )

$\%$ of compounded prescriptions in $\quad 0.359$

terms of prescription dollars

( $\geq 1$ vs. $<1$ 
The Bivariate Association Between the Independent Variables and if the Third Party Require their Participating Pharmacies to Provide Compounding Services.

The analysis for the relationship between the requirement for the pharmacies to provide compounding services and the independent variables is presented in table 15. The analysis revealed significant association for the variable type of third party $(X=4.085, p=0.043)$ with prevalence odds ratio of 0.472. The Chi-square values for the other independent variables ranged from 0.062 (number of subscribers) to 1.164 (number of prescriptions).

Table 15 Summary of bivariate association between the independent variables and if the third party require their participating pharmacies to provide compounding services.

Variable

Type of third party

(For Profit vs. Not For Profit)

Number of prescriptions

$(>500,000$ vs. $<500,000)$

Number of subscribers

$(>100,000$ vs. $<100,000)$

Number of drug benefit models

$(>8$ vs. $\leq 8$ )

$\%$ of compounded prescriptions in terms of total prescription dollars $(\geq 1$ vs. $<1)$
$\underline{X}^{2} \quad$ p-value $\quad \underline{\operatorname{PrOR}} \quad 95 \% \mathrm{CI}$

$\begin{array}{llll}4.085 & 0.043 & 0.472 & 0.228,0.977\end{array}$

$1.164 \quad 0.281$

$0.062 \quad 0.804$

$0.338 \quad 0.561$

$1.162 \quad 0.281$ 
The Bivariate Association Between the Independent Variables and if the Third Party Require their Pharmacists to Provide Compounding Services Within a Specified Period.

The analysis did not showany significant association with the dependent variable. The Chi-square values were 1.256 (number of subscribers), 0.726 (number of subscribers), 1.576 (number of drug benefit models) and 1.233 for the type of third party. The variable percentage of compounded prescriptions had cells too small to count i.e., one of the cells had one respondent. The summary of the analysis is shown in Table 16.

Table 16 Summary of bivariate association between the independent variables and if the third party require their pharmacists to provide compounding services within a specified time period

Variables

Type of third party

(For Profit vs. Not For Profit)

Number of prescriptions

$(>500,000$ vs. $<500,000)$

Number of subscribers

$(>100,000$ vs. $<100,000)$

Number of drug benefit models $(>8$ vs. $\leq 8$ )

$\%$ of compounded prescriptions in CELLS TOO SMALL TO COUNT terms of total prescription dollars

$(\geq 1$ vs. $<1)$ $\underline{x}^{2} \quad \underline{p-v a l u e}$

$1.233 \quad 0.267$

$0.246 \quad 0.620$

$0.268 \quad 0.605$

$\begin{array}{ll}1.576 & 0.209\end{array}$ 


\section{DISCUSSION}

Table 1 showing the demographic characteristics reveal that the majority (72.7\%) of third parties do not have any models under the capitation system. There seems to be a general favor for fee for service and the usual and customary models. In the capitation models the pharmacy receives a set dollar amount per person per time period for providing the needed services to that person for that time period. However the pharmacy has to assume some finanacial risk inherent in the capitation system and hence the pharmacies often resists the capitation models. The third party should have sufficient market strength and market penetration if they want to increase their capitation models. The fee for service models on the other hand are better understood and accepted by both the third party and the pharmacy. Hence there may be less models under the capitated system and a general favor for the fee for service or usual and customary models.

$89.2 \%$ of the respondents in this study do not have a preapproved list. (Table 2). $82.2 \%$ do not require providers to obtain pre approval. Only $4.65 \%$ of the third parties in the study group had both a preapproved list and required providers to obtain pre approval before compounding. $75.97 \%$ did not have a preapproved list and did not require providers to obtain pre approval. The remaining respondents either had a preapproved list or required pre approval but not both. These results are important because no safety or efficacy studies have been conducted on the compounded prescriptions. The prescribers during their course of medical practice may write a prescription that they feel might provide optimum therapeutic effect for the patient. Also the pharmacists based on stability, drug interactions and therapeutic effect of drugs will compound the prescriptions. It is possible that there may be errors while calculating the quantity of drug needed, the uses for which it is to be compounded and the interaction 
among the ingredients in the formula. The results of this study show that without any pre approval requirement or any pre approval process as is the case with the majority of the third party $(75.97 \%)$ there may be no check on what and why the prescription is being compounded. There are no studies that deal specifically with the errors (e.g miscalculation of ingredients, weighing out the wrong quantity of active ingredient) made while compounding prescriptions. In the absence of these studies it is difficult to determine the magnitude of the seriousness of a situation where there is no preapproved list or any pre approval requirement. However based on studies that deal with errors (mislabeling, wrong dose) made by the pharmacist while dispensing non compounded prescriptions (Guernscy B.G \&et al) one might say that there is a distinct likelihood that some or many kinds of errors in compounding prescriptions might be taking place. This is important from the standpoint of saving dollars by not only paying for unnecessarily compounded prescriptions but also from the perspective of safety of the patient. This raises the issue of both quality of care and cost benefit.

The processes of pre approval also vary greatly among the respondents as can be seen from the results shown in Table 2. Majority of them use the phone for the pre approval. A proportion of the third party providers still uses a pre approval form. This raises the question of the number of hours it takes to obtain the pre approval and consequently the number of hours the patient has to wait before receiving the medication. Only $43.5 \%$ of the third party give approval immediately. $34.8 \%$ and $21.7 \%$ of the respondents require 24 and 48 hours respectively to give pre approval. In this case the patient has to wait for a day or two or more than that before receiving their medication. This issue may be serious in some life threatening cases where medication is needed immediately.

About $42.6 \%$ of the respondents do not conduct any drug utilization review on compounded prescriptions (Table 3). Among these, $57.1 \%$ have no 
intention of conducting it in future and $5.4 \%$ are still undecided. Thus it can be said that approximately half of the third party providers in the study group do not currently conduct drug utilization review. When this percentage is combined with the percentage of third party providers that do not have a preapproved list (89.2\%) and do not require pre approval (82.2\%) for compounding, it assumes more importance. When a provider seeks pre approval for a compounded prescription, the insurance company usually checks for the drug, dose and if the drug is included in the formulary if one exists. Drug Utilization Review allows the insurance company to focus on providers who are overprescribing, identify problems with the quality of care, a potential drug abuse problem or problems with compliance with medical treatment on the part of the members. The tighter the pre approval process, the greater the insurance plans ability to manage utilization. An approval process by itself will not automatically control utilzation although it will have an effect.

Of those respondents who conduct a review about $30.1 \%$ conduct retrospective review (i.e. after the prescription has been compounded). Only $9.6 \%$ conduct concurrent review(i.e. when the prescription is compounded). Also of those who conduct review $41.1 \%$ conduct only on the single costly ingredient. This may or may not be the active ingredient in the prescriptions. Also if this is the active ingredient there may be more active ingredients on which the review is not performed since $94.5 \%$ of the third party allow more than one active ingredient to be included per compounded prescription.

As the number of active ingredients in the prescription increases the chances of adverse effects for the patients may also increase. Besides almost all of them perform DUR only on one ingredient. Thus when you combine the number of ingredients allowed in the prescription and the number of ingredients on which DUR is performed the magnitude of the seriousness of the situation 
increases. For example in the case of compounded progesterone suppositories it makes no difference on the number of ingredients on which DUR is performed since it contains only one active ingredient progesterone. However in the case of a compounded prescription containing benadryl and nystatin it makes a difference as to number of ingredients on which DUR is performed.

Third party providers usually clssify prescriptions either by therapeutic class or by individual drugs for conducting DUR. Since compounded prescriptions forms a small portion either as a class or as drugs they are spread over the entire category. Under this situation (if at all) the third party conduct retrospective DUR they cannot avoid the errors that has already been made while compounding the prescription because the review is conducted only after the prescription has been prepared and dispensed. Thus the very purpose for which DUR is conducted viz. patient safety and cutting down unnecessary costs is not served.

Almost all the models reimburse compounded prescriptions (Table 5). However $68.5 \%$ of the third party cannot identify when a drug is compounded for unapproved uses. It is quite likely that a number of these prescriptions might be compounded for some uses for which an FDA approval has not been obtained. Besides $50.4 \%$ of the third party reimburse FDA approved drugs compounded for unapproved uses. This does not check the compounding of drugs for unapproved uses.

Results of the study show that the third parties do not consider dosage form or the time required for compounding into consideration while reimbursing the pharmacists (Table 5). A pharmacist who compound suppositories (consume more time and is difficult to prepare) may be paid the same as a pharmacist who compounds solutions. This may lead to some pharmacies deciding not to compound prescriptions or to compound only selective prescriptions. 
Only $16.2 \%$ of the respondents felt that the number of compounded prescriptions have remained the same (Table 5). $46.92 \%$ were not even aware of the growth of compounded prescriptions. Almost $25 \%$ of the respondents felt that there was an increase in compounded prescriptions. About $5 \%$ felt that there was a decrease. The difference in response maybe due to the fact that compounded prescriptions constitutes only a small proportion of the total prescription volume and as such is considered to play a negligible part in the drug benefit programs. This can be concluded from the results of the percentage of compounded prescriptions in terms of total prescription dollars. A majority of the third party providers (66.4\%) stated that compounded prescriptions only made up less than $1 \%$ of their prescription dollars. $24 \%$ said that it made up $1-5 \%$ of their prescription dollars. When the figure of about two billion prescriptions dispensed per year in community pharmacies converted to its dollar value it assumes more importance.

The results of the bivariate analysis revealed that the variable, number of drug benefit models is associated with some of the dependent variables. There seems to be a positive association between the number of drug benefit models and the presence of preapproved list. The prevalence odds ratio of 3.17 indicates that third party with drug benefit models greater than eight are three times more likely to have a preapproved list than those with relatively less number of models. Those with higher number of models $(>8)$ are also 1.78 times more likely to identify when an FDA approved drug is compounded for unapproved FDA uses. However it is important to note that the confidence interval includes one which indicates that there may or may not be an association. Besides there seems to be an association between the number of drug benefit models and if the third parties allow more than one ingredient per compounded prescription. Third parties with more drug benefit models are only one fifth times more likely to allow more than 
one ingredient per compounded prescription. The inclusion of one in the confidence interval makes it difficult to draw any definite conclusion regarding the association. The third party providers with more drug benefit models are also 2.553 times more likely to be aware of the growth of compounded prescriptions compared to those with relatively less number of models. The reason for this maybe that as the number of drug benefit models increases there is a high likelihood that these plans have better management. The presence of sophisticated controls also increase as the number of plans increases.

There results of the study also revealed an association between the variables, number of prescriptions processed, number of subscribers enrolled and the requirement for preapproval. Third party with prescriptions greater than 500,000 are one third times likely to require preapproval and those with more than 100,000 subscribers are one half times more likely to have the requirement for preapproval compared to those with relatively lesser number of prescriptions and subscribers. The reason for this is that with the increase in the number of prescriptions there maybe a simultaneous increase in the number of compounded prescriptions also. The third party providers who already consider compounded prescriptions to be an insignificant part of their prescription volume and are not aware of the dollar value do not want to expend time and money on the process of preapproval. For those with fewer compounded prescriptions the time and money spent on the preapproval process may be neglible. 


\section{CONCLUSIONS}

The study of the reimbursement of the compounded prescriptions examined several factors related to the reimbursement, review and drug utilization review on compounded prescriptions.

The respondents represented a mix of For Profit Health Insurance Companies, Not For Profit Health Insurance Companies, Health Maintenance Organization, Mail Service Prescription Companies, Pharmacy Benefit Management Companies and Federal/State agencies with varying number of subscribers , prescriptions processed and drug benefit models. The respondents were selected on a national level and hence the results of this study are generalizable to the third party providers throughout U.S.

The study revealed that the majority of the third party providers do not have a preapproved list of compounded prescriptions nor do they require their provider to obtain preapproval. In addition most of them cannot identify when an FDA approved drug is compounded for unapproved uses and almost half of them reimburse for this process. Moreover the third party providers do not conduct drug utilization review on compounded prescriptions. Also among those who conduct the review perform it only on the single costly ingredient and not on all the ingredients. Based on the results of this study, one can conclude that currently there appears to be no consistent check by the third party on how the prescriptions are compounded by the prescriber or the pharmacist.

It is clear from this study that there is a need for the third party to re evaluate their current coverage, review and reimbursement of compounded prescriptions. This study has revealed that there are several areas that need additional study. With the introduction of the NCPDP Telecommunication Standard Format Version 3.2 it is now relatively easy to conduct concurrent DUR 
and DUR on all the ingredients. However cost benefit analysis studies need to be conducted to evaluate the impact of installing version 3.2 for conducting concurrent review, requiring pre approval and conducting DUR on all the ingredients. There is also the need to perform studies to determine the extent of errors made while compounding the prescriptions.

Majority of the third party providers currently do not require all pharmacies to provide compounding services. The third party can assure that atleast one of their participating pharmacy provide the services. Also a provision should be made to provide compounding services within a reasonable period of time.

The rapidly growing segment of the elderly population and the field of biotechnology may lead to an increase in the number of prescriptions compounded in future. Clearly there is a need for the third parties to reevaluate their current coverage, review and reimbursement of compounded prescriptions. 


\section{LIST OF REFERENCES}

1. Vivian, Jesse. "Compounding or Manufacturing?" U.S. Pharmacist. Oct 1994, 112

2. Schwartz, Ronald. "Tuft War?" American Druggist, 10 June 1992

3. $\quad$ Allen, Loyd. "Pharmacy Compounding is a Required Service" . U.S. Pharmacist. June 1994, 114

4. Conlan, Michael. "Compounding vs Manufacturing. Where is the line?" Drug Topics, Oct. 12 1992, 50

5. "Is FDA Usurping Pharmacy Power on Compounding?" Drug Topics. 8 June 1992, 15

6. Bloom, Marlene. "Compounding in Today's Practice". American Pharmacy, Oct. 1991 NS31(10), 32.

7. Martin, Sara. "APhA Secures Pharmacists Right to Compound" . American Pharmacy. Nov. 1992 NS32(11), 26

8. Pharmaceutical Benefits Under State Medicaid Assistance Programs, Sept. 1990 


\section{APPENDICES}




\section{IIIIIIIIIII

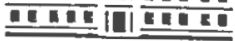

UNIVERSITY OF

RHODE ISLAND

\section{APPENDIX A1}

December 12,1994

Dear Sir or Madam,

The enclosed survey is an attempt to determine third party coverage policy and management of compounded prescriptions. Specific areas such as drug utilization review, preapproval and reimbursement scheme are included in this survey. The survey is part of my thesis project towards my Master of Sciences in Pharmacy

Administration. You are assured of anonymity since nowhere in this survey have I requested you to identify yourself. I would be very happy if you could return the questionnaire by 15 th January 1995 in the enclosed self addressed prestamped envelope.

Your responses and opinions will be appreciated. If you have any questions or suggestions please feel free to contact me at 401-792-2789 or write to me.

Thank you for the time you have spent in completing my questionnaire.

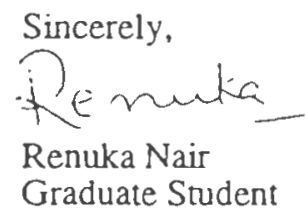

cc: A .Taubman, R.Ph.,Ph.D Major Professor 



\section{APPENDIX A}

January 23.1995

Dear Sir or Madarn.

The enclosed survey is a follow up of my earlier questionnaire that was mailed to you in December 1994. This survey is an attempt to determine third party coverage policy and management of compounded prescriptions. Specific areas such as drug utilization review, pre approval and reimbursement scheme are included in this survey. The survey is part of my thesis project towards my Master of Sciences in Pharmacy Administration. If for some reasons you were unable to return the earlier questionnaire, I would appreciate if you will fill this out and return it by 20th February 1995 in the enclosed self addressed pre stamped envelope. If you have already mailed the previous questionnaire please do not return this again. You are assured of anonymity since nowhere in this survey have I requested you to identify yourself.

Your responses and opinions wil! be appreciated. If you have any questions or suggescions please feel free to contact me at 401-792-2789 or write to me.

Thank you for the ume you have spent in completing my questionnaire.

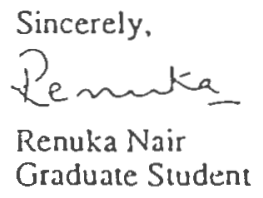

cc: A .Taubman, R.Ph.,Ph.D

Major Professor

Thesuming of

COLLEGE OF PHARMACY, DEPARTMENT OF PHARMACEUTIOS

Kingsion, Rhode lsland 0288;-0809

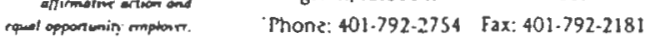




\section{APPENDIX B}

The following list of questions pertains to reimbursement of compounded prescriptions that might be included under your pharmacy benefit programs. I request you to kindly fill out the questionnaire and return it in the enclosed self addressed envelope. If you have any questions, feel free to contact me at 401-789-2789.

Thank you,

Yours sincerely,

Renuka Nair

1. Select the one that best describes your company.

1. For profit health insurance company

2. Not for profit health insurance company

3. Health maintenance organization

4. Mail service prescription company

5. Pharmacy benefit management company

6. Federal/State agency

2. Total number of prescriptions(compounded \& non compounded) processed during the calendar year 1993.
1. $0-50,000$
4. $500,000-1,000,000$
2. $50,000-100,000$
5. More than $1,000,000$
3. $100,000-500,000$

3. Total number of subscribers (enrolles \& dependents) enrolled under the drug benefit program during the calendar year 1993.
1. $0-5,000$
5. $100,000-500,000$
2. $5,000-10,000$
6. $500,000-1,000,000$
3. $10,000-50,000$
7. More than $1,000,000$
4. $50,000-100,000$

4. Do you require the pharmacist to differentiate between non compounded and compounded prescriptions for reimbursement?
1. Yes
2. No

5. How many drug benefit models do you ad minister?

1. None

Capitation Fee for service U \& C Other

2. One

3. Two

4. Three

5. Four

6. More than four 


\section{APPENDIX B}

6. Indicate the type of models that reimburse compounded prescriptions.

1. None

All models Some models None

2. One

3. Two

4. Three

5. Four

6. More than four

7. For those plans that do not presently reimburse compounded prescriptions, do you intend reimbursing them in future?

1. Yes, within the next year

2. Yes, within the next two years

3. Yes, after two years

4. No

8. Do you have a preapproved list of prescriptions to be compounded?
1. Yes
2. No

9. Are you able to identify when an FDA approved drug is being $c$ compounded for unapproved uses?
1. Yes
2. No

10. Do you reimburse for FDA approved drugs compounded for unapproved uses?
1. Yes
2. No

11. Do you require that the provider obtain preapproval before he/she can compound and receive reimbursement?
1. Yes
2. No (If no, skip to question 15 )

12. Indicate the person responsible for obtaining preapproval from your company (CHECK ALL THAT APPLY)
1. Yes
2. No

13. Check the process for obtaining preapproval (CHECK ALL THAT APPLY)
i. Prior approval form
4. Approval by fax
2. Approval via computer
5. Other (SPECIFY)
3. Approval over computer 


\section{APPENDIX B}

14. Indicate the number of hours it takes to obtain approval.
1. Immediately
3. Within 48 hours
2. Within 24 hours
4. More than 48 hours

15. Define the formulas (e.g. EAC + Dispensing fee) of the following types of reimbursement schemes..

1. Fee for service

2. Capitation

3. Usual and customary

4. Other (SPECIFY)

16. Does the reimbursement scheme vary according to the type of prescriptions? (CHECK ALL THAT APPLY)

1. Yes, they differ according to the dosage form

2. Yes, they differ based on the time required for compounding

3. No

4. Other (SPECIFY)

17. Do you conduct Drug Utilization Review on compounded prescriptions?

1. Yes

2. No (IF NO PLEASE ANSWER 17A)

17A. Do you intend conducting them in future?

1. Yes, within the next year

2. Yes, within the next two years

3. Yes, after two years

4. No

18. What kind of Drug Utilization Review do you conduct? (CHECK ALL THAT APPLY)

1. Prospective i.e. conducting review before time of dispensing

2. Concurrent i.e. conducting review at time of dispensing

3. Retrospective i.e. conducting review after time of dispensing

19. Do you conduct Drug Utilization Review only on the single most costly ingredient?

1. Yes, only on the costly ingredient

2. On all the ingredients in the formula

3. Other (SPECIFY) 


\section{APPENDIX B}

20. Do you allow more than one active ingredient per compounded prescription?
1. Yes
2. No

21. Has the number of compounded prescriptions increased over the last two years? (Skip to question 23)

1. Increased by $0-5 \%$

2. Increased by $6-10 \%$

3. Increased by $11-15 \%$
4. Increased by $16-20 \%$

5. Remained the same

6. Don't know

22. Has the number of compounded prescriptions decreased over the last two years?

1. Decreased by $0-5 \%$

2. Decreased by $6-10 \%$

3. Decreased by $11-15 \%$
4. Decreased by $16-20 \%$

5. Remained the same

6. Don't know

23. What percentage of total prescription dollars constitute compounding?
1. Less than $1 \%$
4. $6 \%-10 \%$
2. $1 \%-5 \%$
5. More than $10 \%$

24. Do you require that all your participating pharmacies compound drugs?

1. Yes, in all the models

2. Yes, in some models

3. No

25. Do you require that the participating pharmacists provide compounding services within a reasonable period of time?

1. Yes, within 24 hours

2. Yes, more than 24 hours

3. No

Once again if you have any questions or concerns feel free to contact me at 401-792-2789 or write to me.

\section{PLEASE RETURN IN THE ENCLOSED SELF ADDRESSED PRESTAMPED ENVELOPE}

\section{THANK YOU}


OPTIONS LS $=80$;

PROC FORMAT;

VALUE ABCFMT $1=$ 'FOR PROFIT HEALTH INSURANCE COMPANY'

$2=$ 'NOT FOR PROFIT INSURANCE COMPANY'

$3=$ 'HEALTH MAINTENANCE ORGANIZATION'

$4=$ 'MAIL SERVICE PRESCRIPTION COMPANY'

$5=$ ' PHARMACY BENEFIT MANAGEMENT COMPANY'

$6=$ ' FEDERAL/STATE AGENCY' ;

VALUE DEFFMT $1=' 0-50000^{\prime}$

$2=' 50000-100000^{\prime}$

$3=' 100000-500000^{\prime}$

$4=' 500000-1000000^{\prime}$

$5=$ 'MORE THAN 1000000 ';

VALUE GHIFMT $1=10-5000^{\prime}$

$2=' 5000-10000^{\prime}$

$3=' 10000-50000^{\prime}$

$4={ }^{\prime} 50000-100000^{\prime}$

$5=' 100000-500000^{\prime}$

$6=' 500000-1000000$ '

$7='$ MORE THAN 1000000';

VALUE JKLFMT 1='YES'

$2=$ 'NO';

VALUE MNO $1=$ 'NONE'

$2=$ ' ONE'

$3=$ ' TWO'

$4=$ ' THREE'

$5=$ ' FOUR'

$6=$ 'MORE THAN FOUR';

VALUE MNOX $1=$ 'NONE'

$2={ }^{\prime} \mathrm{ONE}^{\prime}$

$3=$ ' TWO'

$4=$ ' THREE '

$5=$ ' FOUR'

$6=$ 'MORE THAN FOUR';

VALUE MNOY $1=$ 'NONE'

$2={ }^{\prime} \mathrm{ONE}$ '

$3=$ ' TWO'

$4=$ ' THREE '

$5=$ ' FOUR'

$6=$ 'MORE THAN FOUR';

VALUE MNOZ $1=$ 'NONE'

$2=$ ' ONE'

$3=$ ' TWO'

$4=$ ' THREE'

$5=$ ' FOUR' 


$$
6=\text { 'MORE THAN FOUR'; }
$$

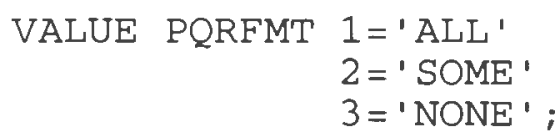

VALUE PQRXFMT $1=$ 'ALL'

$2=$ 'SOME'

$3=$ ' NONE' ;

VALUE PQRYFMT $1=$ 'ALL'

$2=$ 'SOME'

$3={ }^{\prime}$ NONE' '

VALUE PQRZFMT $1=$ 'ALL'

$2=$ ' SOME'

$3={ }^{\prime}$ NONE ' ;

VALUE STUFMT $1=$ 'YES NEXT YEAR'

2 ='YES NEXT 2 YEARS'

$3=$ 'YES AFTER 2 YEARS'

$4=$ 'NO'

$5=$ 'NOT APPLICABLE' ;

VALUE VWXFMT $1=$ 'YES'

$2={ }^{\prime} \mathrm{NO}$ ' ;

VALUE YZFMT $1=$ 'YES'

$2={ }^{\prime} \mathrm{NO}^{\prime}$;

VALUE ABCAFMT $1=$ 'YES'

$2={ }^{\prime} \mathrm{NO}$ ' ;

VALUE DEFAFMT $1=$ 'YES'

$2={ }^{\prime} \mathrm{NO}$ ' ;

VALUE GHIAFMT 1 ='PRESCRIBER'

2 = ' PHARMACIST'

$3=$ ' OTHER'

$4=$ 'NOT APPLICABLE'

5='EITHER PRES OR PHARM';

VALUE JKLAFMT $01=$ 'FORM'

$02=$ ' COMPUTER '

$03=$ ' PHONE '

$04=$ ' FAX'

$05=$ ' OTHER'

$06=$ 'NOT APPLICABLE'

$07=$ 'FORM + PHONE+FAX'

$08=$ ' $\mathrm{FORM}+\mathrm{FAX}$ '

$09=$ ' $\mathrm{PHONE}+\mathrm{FAX}$ '

$10=$ ' FORM+COMPUTER + PHONE '

$11=$ ' ALL'

$12={ }^{\prime} F O R M+P H O N E+F A X '$ 
$13={ }^{\prime} \mathrm{PHONE}+\mathrm{FAX}+\mathrm{COMPUTER}$ '

$14=$ ' COMPUTER+PHONE' ' ;

VALUE MNOAFMT 1=' IMMEDIATELY'

$2=$ 'WITHIN $24 \mathrm{H}^{\prime}$

$3=$ 'WITHIN $48 \mathrm{H}^{\prime}$

$4=$ 'MORE THAN $48 \mathrm{H}^{\prime}$

$5=$ 'NOT APPLICABLE' ;

VALUE PQRAFMT $1=$ 'FEE FOR SERVICE'

$2=$ ' CAPITATION'

$3={ }^{\prime} U \$ C C^{\prime}$

$4=$ ' OTHER ' $^{\prime}$

$5=$ ' FEE+CAPITATION'

$6=' \mathrm{FEE}+\mathrm{CAP}+\mathrm{UC}$ '

$7={ }^{\prime} \mathrm{CAP}+\mathrm{UC}$ '

$8=' \mathrm{FEE}+\mathrm{CAP}$ '

$9=$ ' ALL' ;

VALUE STUAFMT $1=$ 'YES-DOSAGE'

2 = 'YES-TIME'

$3={ }^{\prime} \mathrm{NO}$ '

$4=$ ' OTHER'

$5=$ 'ON DOSAGE \& TIME' ;

VALUE VWXAFMT $1=$ 'YES'

$2={ }^{\prime} \mathrm{NO}^{\prime}$;

VALUE YZAFMT $1=$ 'YES NEXT YEAR'

$2=$ 'YES IN NEXT 2 YEARS'

$3=$ 'YES AFTER 2YRS'

$4={ }^{\prime}$ NO'

$5=$ 'NOT APPLICABLE'

$6=$ 'DONT KNOW' ;

VALUE ABCBFMT $1=$ 'PROSPECTIVE'

$2=$ ' CONCURRENT'

$3=$ ' RETROSPECTIVE'

$4={ }^{\prime}$ ALL'

$5={ }^{\prime} \mathrm{CON}+\mathrm{RETRO}$ '

$6=$ 'NOT APPLICABLE'

$7=$ ' PROS + RETRO'

$8={ }^{\prime}$ PROS + CON' ;

VALUE ABAFMT $1=$ 'YES ON COSTLY INGREDIENT'

$2=$ 'YES ON ALL'

$3=$ ' OTHER'

$4=$ 'NOT APPLICABLE' $5=$ 'EITHER ON COSTLY OR ALL';

VALUE CDAFMT $1=$ 'YES'

$2={ }^{\prime} \mathrm{NO}^{\prime} ;$ 


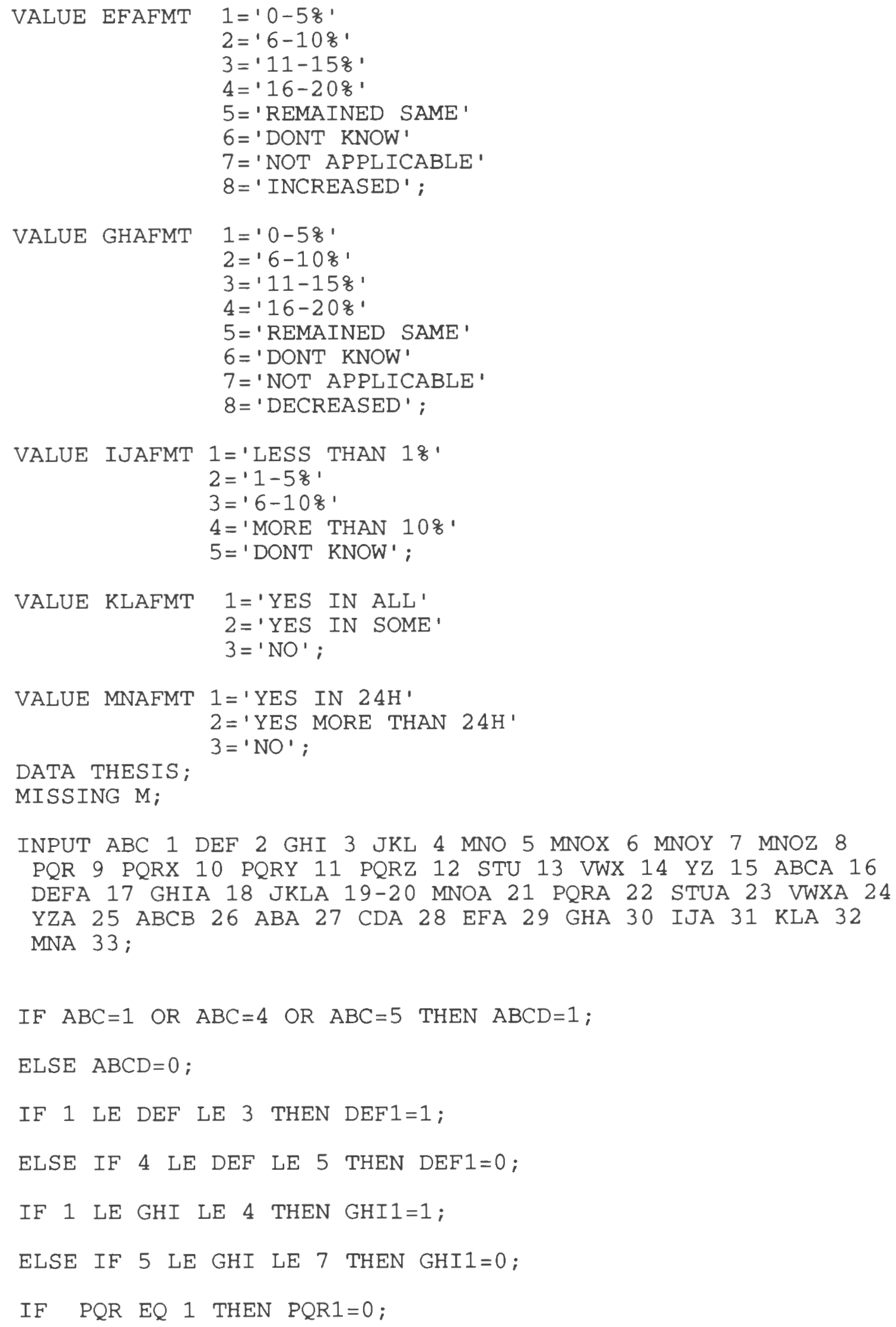


ELSE IF PQR EQ 2 OR 3 THEN PQR1=1;

IF PQRX EQ 1 THEN PQRX1=0;

ELSE IF PQRX EQ 2 OR 3 THEN PQRX1 =1;

IF PQRY EQ 1 THEN PQRY1=0;

ELSE IF PQRY EQ 2 OR 3 THEN PQRY1=1;

IF PQRZ EQ 1 THEN PQRZ=0;

ELSE IF PQRZ EQ 2 OR 3 THEN PQRZ=1;

IF MNO EQ 1 THEN PQRX=.;

IF MNOX EQ 1 THEN $\mathrm{PQR}=$.;

IF MNOY EQ 1 THEN PQRY=.;

IF MNOZ EQ 1 THEN PQRZ=.;

IF 1 LE STU LE 3 THEN STU1=1;

ELSE IF STU=4 THEN STU1=0;

IF $\quad$ STU $=5$ THEN STU $=$. ;

IF GHIA=4 THEN GHIA= ;

IF JKLA $=6$ THEN JKLA = ;

IF $\quad \mathrm{MNOA}=5$ THEN $\mathrm{MNOA}=$.;

IF 1 LE STUA LE 2 THEN STUA1=0;

ELSE IF STUA=3 THEN STUA1=1;

ELSE IF STUA EQ 4 OR 5 THEN STUA1=0;

IF 1 LE YZA LE 3 THEN YZAI=0;

ELSE IF YZA EQ 4 THEN YZA1=1;

ELSE IF YZA=5 THEN YZA= .;

IF ABA EQ 1 THEN ABA1=0;

ELSE IF 2 LE ABA LE 3 THEN ABA1=1;

ELSE IF ABA EQ 4 THEN ABA=.; 


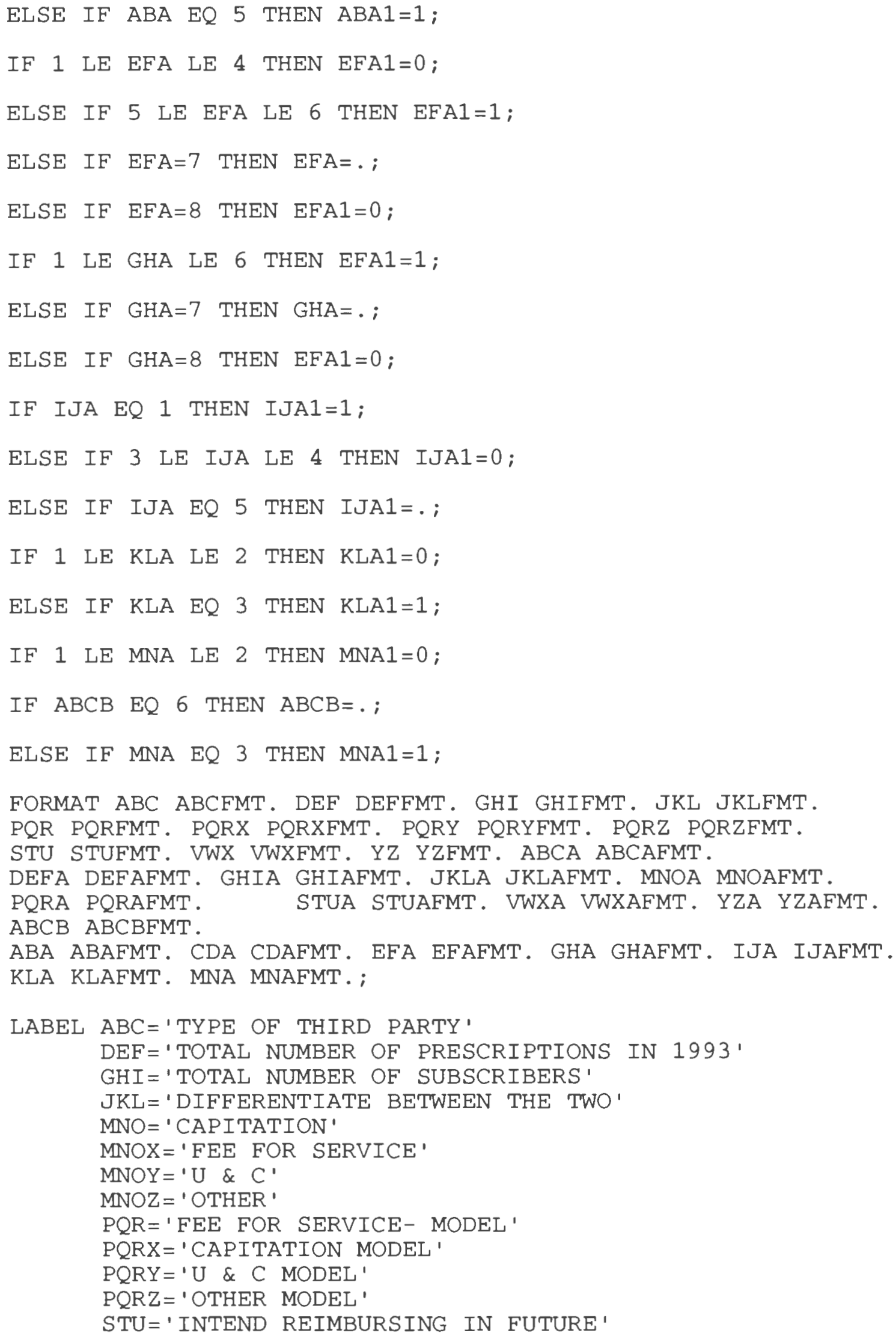




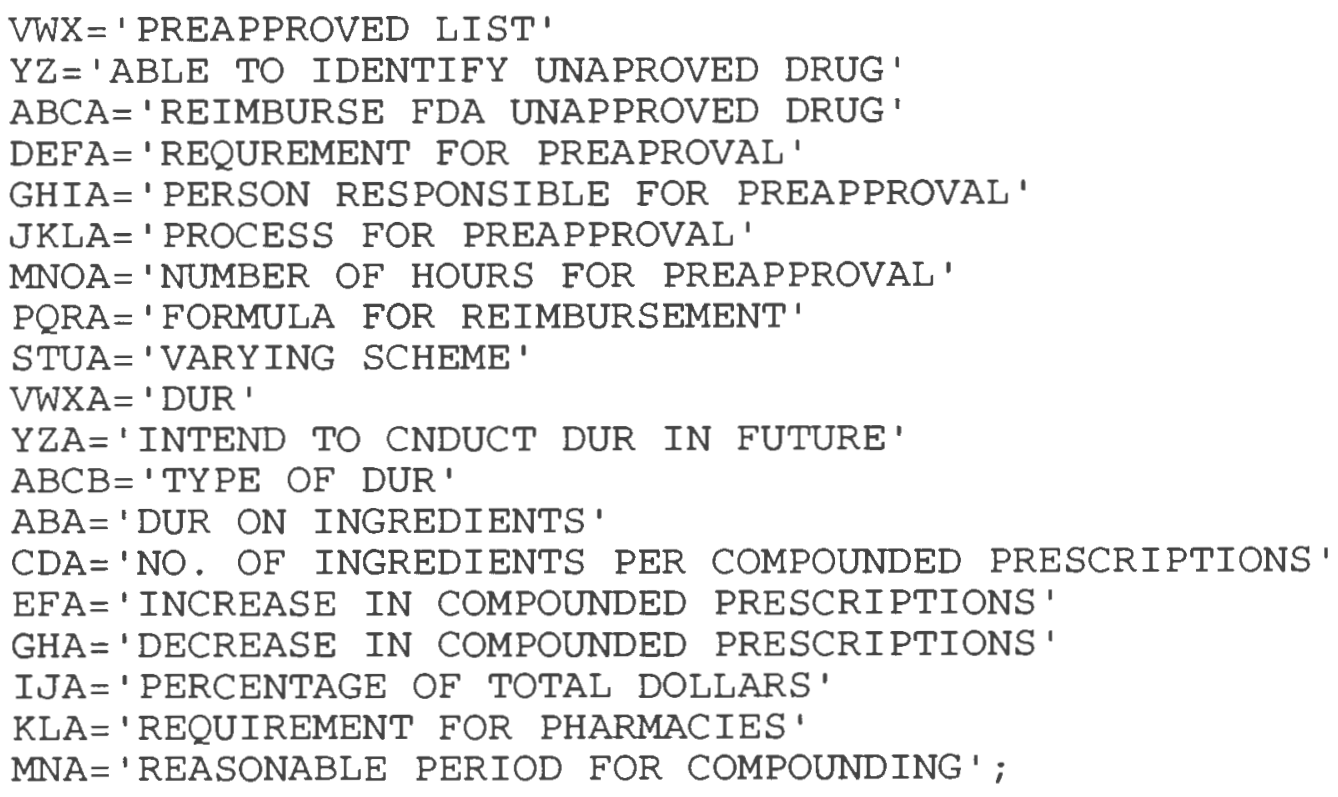

\section{THE DATA HAS BEEN DELETED TO SAVE SPACE}

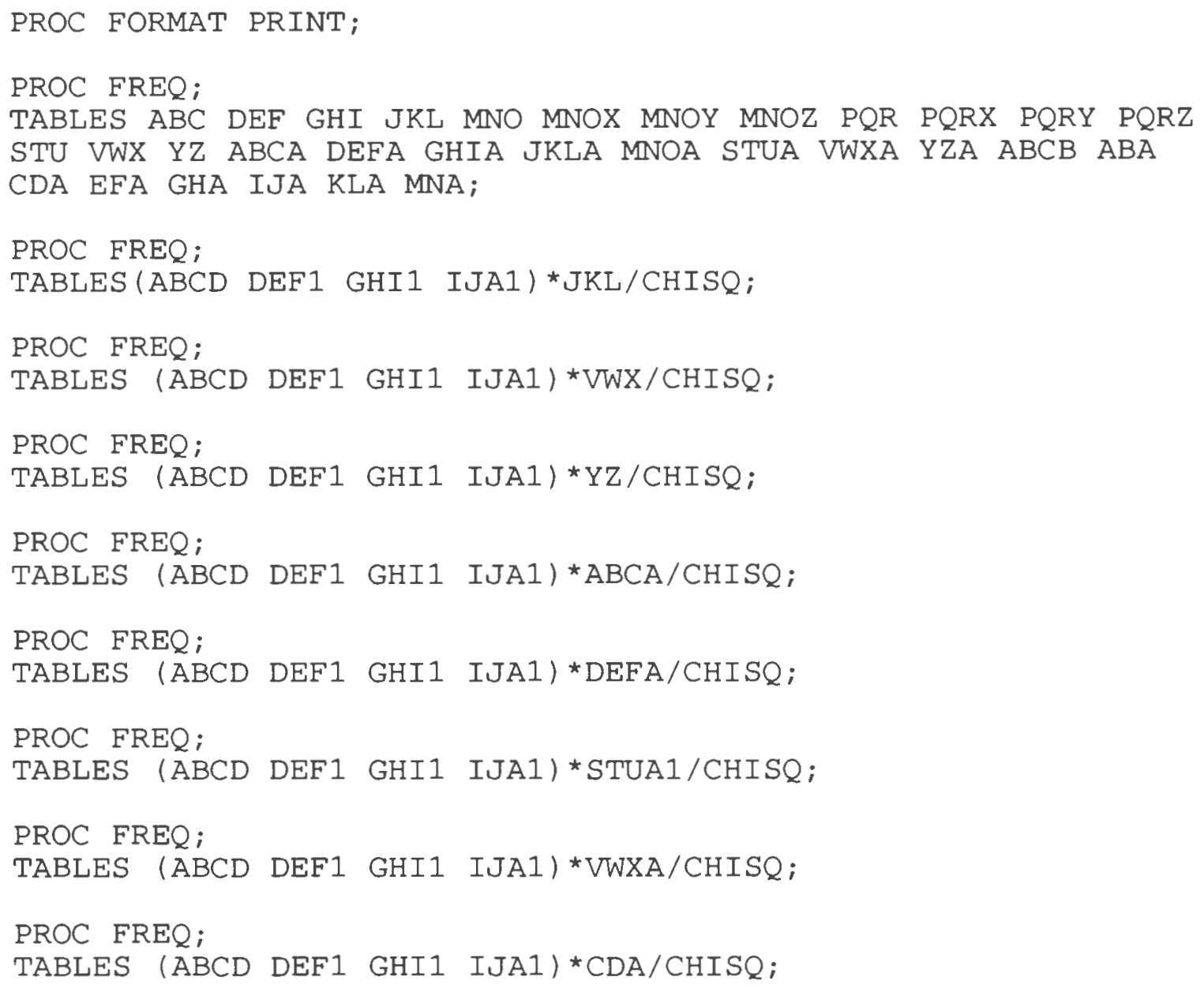


PROC FREQ;

TABLES (ABCD DEF1 GHI1 IJA1) *EFA1/CHISQ;

PROC FREQ;

TABLES (ABCD DEF1 GHI1 IJA1) *KLA1/CHISQ;

PROC FREQ;

TABLES (ABCD DEF1 GHI1 IJA1) *MNA1/CHISQ;

PROC FREQ;

TABLES VWX ${ }^{*}$ DEFA;

PROC FREQ;

TABLES IJA*DEF;

PROC FREQ; TABLES MNO*MNOX *MNOY*MNOZ; 
TYPE OF THIRD PARTY

$\begin{array}{lrrrr}\text { ABC } & \text { Frequency } & \text { Percent } & \begin{array}{c}\text { Cumulative } \\ \text { Frequency }\end{array} & \begin{array}{c}\text { Cumulative } \\ \text { Percent }\end{array} \\ \text { FOR PROFIT HEALT } & 8 & 6.2 & 8 & 6.2 \\ \text { NOT FOR PROFIT I } & 25 & 19.4 & 33 & 25.6 \\ \text { HEALTH MAINTENAN } & 15 & 11.6 & 48 & 37.2 \\ \text { MAIL SERVICE PRE } & 6 & 4.7 & 54 & 41.9 \\ \text { PHARMACY BENEFIT } & 40 & 31.0 & 94 & 72.9 \\ \text { FEDERAL/STATE AG } & 35 & 27.1 & 129 & 100.0 \\ & \text { Frequency Missing }=1 & & \end{array}$

TOTAI NUMBER OF PRESCRIPTIONS PROCESSED IN 1993

$\begin{array}{lrcrr}\text { DEF } & \text { Frequency } & \text { Percent } & \begin{array}{c}\text { Cumulative } \\ \text { Frequency }\end{array} & \begin{array}{c}\text { Cumulative } \\ \text { Percent }\end{array} \\ 0-50000 & 12 & 9.4 & 12 & 9.4 \\ 50000-100000 & 4 & 3.1 & 16 & 12.6 \\ 100000-500000 & 10 & 7.9 & 26 & 20.5 \\ 500000-1000000 & 21 & 16.5 & 47 & 37.0 \\ \text { MORE THAN 100000 } & 80 & 63.0 & 127 & 100.0\end{array}$

Frequency Missing $=3$

TOTAL NUMBER OF SUBSCRIBERS ENROLLED IN 1993

$\begin{array}{lcccc} & \text { GHI } & \text { Frequency } & \begin{array}{c}\text { Cumulative } \\ \text { Percent }\end{array} & \begin{array}{c}\text { Cumulative } \\ \text { Frequency }\end{array} \\ \text { Percent }\end{array}$

Frequency Missing $=2$

ABLE TO DIFFERENTIATE BETWEEN COMPOUNDED AND NON COMPOUNDED PRESCRIPTIONS

\begin{tabular}{lcccc} 
JKL & Frequency & Percent & $\begin{array}{c}\text { Cumulative } \\
\text { Frequency }\end{array}$ & $\begin{array}{c}\text { Cumulative } \\
\text { Percent }\end{array}$ \\
\hline YES & 106 & 82.2 & 106 & 82.2 \\
NO & 23 & 17.8 & 129 & 100.0 \\
& &
\end{tabular}




\begin{tabular}{crrrr} 
CAPITATION \\
MNO & Frequency & Percent & $\begin{array}{r}\text { Cumulative } \\
\text { Frequency }\end{array}$ & $\begin{array}{c}\text { Curnulative } \\
\text { Percent }\end{array}$ \\
\hdashline 1 & 91 & 72.2 & 91 & 72.2 \\
2 & 6 & 4.8 & 97 & 77.0 \\
3 & 11 & 8.7 & 108 & 85.7 \\
4 & 1 & 0.8 & 109 & 86.5 \\
5 & 3 & 2.4 & 112 & 88.9 \\
6 & 14 & 11.1 & 126 & 100.0
\end{tabular}

FEE FOR SERVICE

$\begin{array}{crrrr}\text { MNOX } & \text { Frequency } & \text { Percent } & \begin{array}{c}\text { Cumulative } \\ \text { Frequency }\end{array} & \begin{array}{c}\text { Cumulative } \\ \text { Percent }\end{array} \\ 1 & 18 & 14.3 & 18 & 14.3 \\ 2 & 29 & 23.0 & 47 & 37.3 \\ 3 & 10 & 7.9 & 57 & 45.2 \\ 4 & 4 & 3.2 & 61 & 48.4 \\ 5 & 5 & 4.0 & 66 & 52.4 \\ 6 & 60 & 47.6 & 126 & 100.0 \\ & & \end{array}$

\begin{tabular}{ccccc} 
U\&C \\
MNOY & Frequency & Percent & $\begin{array}{r}\text { Cumulative } \\
\text { Frequency }\end{array}$ & $\begin{array}{r}\text { Cumulative } \\
\text { Percent }\end{array}$ \\
\hline 1 & 59 & 46.8 & 59 & 46.8 \\
2 & 17 & 13.5 & 76 & 60.3 \\
3 & 12 & 9.5 & 88 & 69.8 \\
4 & 2 & 1.6 & 90 & 71.4 \\
5 & 2 & 1.6 & 92 & 73.0 \\
6 & 34 & 27.0 & 126 & 100.0 \\
\multicolumn{5}{c}{ Frequency Missing $=4$} \\
\end{tabular}

REIMBURSE FEE FOR SERVICE- MODEL

\begin{tabular}{lcccc} 
PQR & Frequency & Percent & $\begin{array}{c}\text { Cumulative } \\
\text { Frequency }\end{array}$ & $\begin{array}{c}\text { Cumulative } \\
\text { Percent }\end{array}$ \\
\hline ALL & 102 & 93.6 & 102 & 93.6 \\
SOME & 6 & 5.5 & 108 & 99.1 \\
NONE & 1 & 0.9 & 109 & 100.0 \\
& &
\end{tabular}




\section{REIMBURSE CAPITATION MODEL}

\begin{tabular}{lcccc} 
PQRX & Frequency & Percent & $\begin{array}{r}\text { Cumulative } \\
\text { Frequency }\end{array}$ & $\begin{array}{c}\text { Cumulative } \\
\text { Percent }\end{array}$ \\
\hline ALL & 31 & 83.8 & 31 & 83.8 \\
SOME & 5 & 13.5 & 36 & 97.3 \\
NONE & 1 & 2.7 & 37 & 100.0 \\
& \multicolumn{4}{c}{ Frequency Missing $=93$}
\end{tabular}

REIMBURSE U \& C MODEL

\begin{tabular}{lcccc} 
PQRY & Frequency & Percent & $\begin{array}{c}\text { Cumulative } \\
\text { Frequency }\end{array}$ & $\begin{array}{c}\text { Cumulative } \\
\text { Percent }\end{array}$ \\
\hline ALL & 59 & 85.5 & 59 & 85.5 \\
SOME & 6 & 8.7 & 65 & 94.2 \\
NONE & 4 & 5.8 & 69 & 100.0
\end{tabular}

Frequency Missing $=61$

INTEND REIMBURSING IN FUTURE

$\begin{array}{lrrrr} & \text { STU } & \text { Frequency } & \text { Cumulative } & \begin{array}{c}\text { Cumulative } \\ \text { Percent }\end{array} \\ \text { Frequency } & \begin{array}{c}\text { Percent } \\ \text { YES NEXT YEAR }\end{array} \\ \text { NO } & 2 & 33.3 & 2 & 33.3 \\ \text { Frequency Missing }=124 & \end{array}$

\begin{tabular}{lcccc} 
PREAPROVED LIST \\
VWX & Frequency & Percent & $\begin{array}{c}\text { Cumulative } \\
\text { Frequency }\end{array}$ & $\begin{array}{c}\text { Cumulative } \\
\text { Percent }\end{array}$ \\
\hdashline-14 & 10.8 & 14 & 10.8 \\
YES & 14 & 89.2 & 130 & 100.0
\end{tabular}

ABLE TO IDENTIFY UNAPROVED DRUG

$\begin{array}{lcccc}\text { YZ } & \text { Frequency } & \text { Percent } & \begin{array}{c}\text { Cumulative } \\ \text { Frequency }\end{array} & \begin{array}{c}\text { Cumulative } \\ \text { Percent }\end{array} \\ - & & & \\ \text { YES } & 41 & 31.5 & 41 & 31.5 \\ \text { NO } & 89 & 68.5 & 130 & 100.0\end{array}$




\section{REIMBURSE FDA UNAPPROVED DRUG USES}

\begin{tabular}{lcccc} 
ABCA & Frequency & Percent & $\begin{array}{c}\text { Cumulative } \\
\text { Frequency }\end{array}$ & $\begin{array}{c}\text { Cumulative } \\
\text { Percent }\end{array}$ \\
\hline YES & 64 & 50.4 & 64 & 50.4 \\
NO & 63 & 49.6 & 127 & 100.0 \\
& & &
\end{tabular}

REQUREMENT FOR PREAPROVAL

\begin{tabular}{lcccc} 
DEFA & Frequency & Percent & $\begin{array}{c}\text { Cumulative } \\
\text { Frequency }\end{array}$ & $\begin{array}{c}\text { Cumulative } \\
\text { Percent }\end{array}$ \\
\hline YES & 23 & 17.8 & 23 & 17.8 \\
NO & 106 & 82.2 & 129 & 100.0 \\
& Frequency Missing $=1$ &
\end{tabular}

PERSON RESPONSIBLE FOR PREAPPROVAL

\begin{tabular}{|c|c|c|c|c|c|}
\hline & GHIA & Frequency & Percent & $\begin{array}{l}\text { Cumulative } \\
\text { Frequency }\end{array}$ & $\begin{array}{c}\text { Cumulative } \\
\text { Percent }\end{array}$ \\
\hline PRESCR IBER & & 5 & 217 & $\cdots \cdots+\cdots$ & 217 \\
\hline PHARMACIST & & 11 & $\begin{array}{l}21.7 \\
47.8\end{array}$ & $\begin{array}{r}5 \\
16\end{array}$ & $\begin{array}{l}21.7 \\
69.6\end{array}$ \\
\hline EITHER PRES & OR $P$ & 7 & 30.4 & 23 & 100.0 \\
\hline
\end{tabular}

Erequency Missing $=107$

PROCESS FOR PREAPPROVAL

$\begin{array}{lcccr} & \text { JKLA } & \text { Frequency } & \begin{array}{c}\text { Cumulative } \\ \text { Percent }\end{array} & \begin{array}{c}\text { Cumulative } \\ \text { Frequency }\end{array} \\ \text { Percent } \\ \text { FORM } & 2 & 8.7 & 2 & 8.7 \\ \text { COMPUTER } & 1 & 4.3 & 3 & 13.0 \\ \text { PHONE } & 7 & 30.4 & 10 & 43.5 \\ \text { FORM + PHONE+FAX } & 4 & 17.4 & 14 & 60.9 \\ \text { FORM+FAX } & 1 & 4.3 & 15 & 65.2 \\ \text { PHONE+FAX } & 1 & 4.3 & 16 & 69.6 \\ \text { FORM+COMPUTER+PH } & 3 & 13.0 & 19 & 82.6 \\ \text { ALL } & 2 & 8.7 & 21 & 91.3 \\ \text { PHONE+FAX+COMPUT } & 1 & 4.3 & 22 & 95.7 \\ \text { COMPUTER+PHONE } & 1 & 4.3 & 23 & 100.0\end{array}$

Frequency Missing $=107$ 


\begin{tabular}{|c|c|c|c|c|}
\hline MNOA & Frequency & Percent & $\begin{array}{c}\text { Cumulative } \\
\text { Frequency }\end{array}$ & $\begin{array}{c}\text { Cumulative } \\
\text { Percent }\end{array}$ \\
\hline - - - - - - - & & ------- & $---\cdots--\cdots-\cdots$ & ---------1 \\
\hline IMMEDIATELY & 10 & 43.5 & 10 & 43.5 \\
\hline WITHIN $24 \mathrm{H}$ & 8 & 34.8 & 18 & 78.3 \\
\hline WITHIN $48 \mathrm{H}$ & 5 & 21.7 & 23 & 100.0 \\
\hline
\end{tabular}

Frequency Missing $=107$

FACTORS AFFECTING THE REIMBURSEMENT SCHEME

\begin{tabular}{|c|c|c|c|c|}
\hline STUA & Frequency & Percent & $\begin{array}{l}\text { Cumulative } \\
\text { Frequency }\end{array}$ & $\begin{array}{c}\text { Cumulative } \\
\text { Percent }\end{array}$ \\
\hline YES-DOSAGE & 5 & 4.0 & 5 & 40 \\
\hline YES-TIME & 10 & 8.0 & 15 & 12.0 \\
\hline NO & 97 & 77.6 & 112 & 89.6 \\
\hline OTHER & 6 & $4 \cdot 8$ & 118 & 94.4 \\
\hline ON DOSAGE \& TIME & 7 & 5.6 & 125 & 100.0 \\
\hline
\end{tabular}

\begin{tabular}{lrrrr}
\multicolumn{4}{c}{ DUR } \\
VWXA & Frequency & Percent & $\begin{array}{c}\text { Cumulative } \\
\text { Frequency }\end{array}$ & $\begin{array}{c}\text { Cumulative } \\
\text { Percent }\end{array}$ \\
\hdashline YES & 74 & 57.4 & 74 & 57.4 \\
NO & 55 & 42.6 & 129 & 100.0 \\
& Frequency Missing $=1$
\end{tabular}

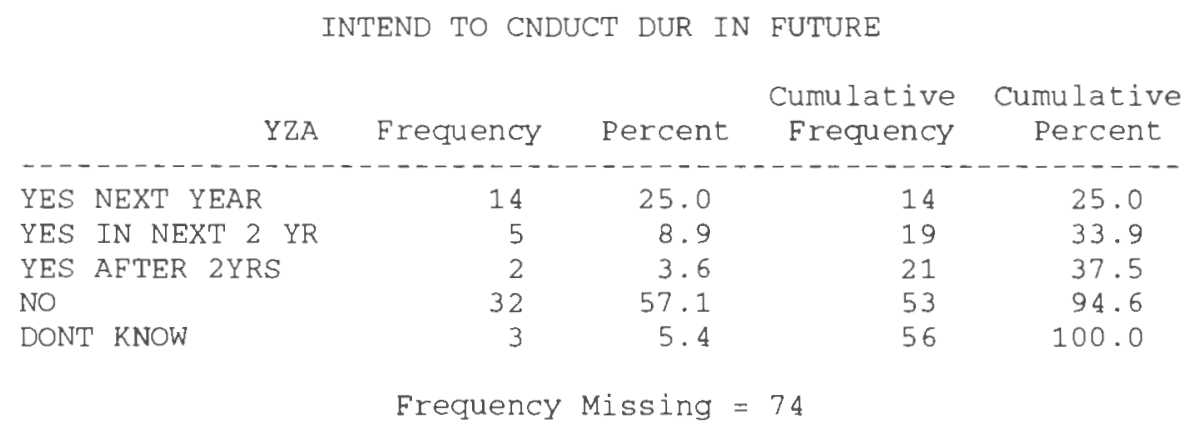


TYPE OF DUR

\begin{tabular}{|c|c|c|c|c|}
\hline $\mathrm{ABCB}$ & Frequency & Percent & $\begin{array}{l}\text { Cumulative } \\
\text { Frequency }\end{array}$ & $\begin{array}{c}\text { Cumulative } \\
\text { Percent }\end{array}$ \\
\hline PROSPECTIVE & 4 & 5.5 & 4 & 5.5 \\
\hline CONCURRENT & 7 & 9.6 & 11 & 15.1 \\
\hline RETROSPECTIVE & 22 & 30.1 & 33 & 45.2 \\
\hline ALI & 19 & 26.0 & 52 & 71.2 \\
\hline CON+RETRO & 14 & 19.2 & 66 & 90.4 \\
\hline PROS+RETRO & 6 & 8.2 & 72 & 98.6 \\
\hline PROS+CON & 1 & 1.4 & 73 & 100.0 \\
\hline
\end{tabular}

Frequency Missing $=57$

DUR ON INGREDIENTS

\begin{tabular}{lcccc} 
ABA & Frequency & Percent & $\begin{array}{c}\text { Cumulative } \\
\text { Frequency }\end{array}$ & $\begin{array}{c}\text { Cumulative } \\
\text { Percent }\end{array}$ \\
\hline YES ON COSTLY IN & 30 & 41.1 & 30 & 41.1 \\
YES ON ALL & 38 & 52.1 & 68 & 93.2 \\
EITHER ON COSTLY & 5 & 6.8 & 75 & 100.0
\end{tabular}

Frequency Missing $=57$

ALLOW MORE THAN 1 ACTIVE INGREDIENT PER COMPOUNDED PRESCRIPTION

\begin{tabular}{lcccc} 
CDA & Frequency & Percent & $\begin{array}{c}\text { Cumulative } \\
\text { Frequency }\end{array}$ & $\begin{array}{c}\text { Cumulative } \\
\text { Percent }\end{array}$ \\
\hline YES & 121 & 94.5 & 121 & 94.5 \\
NO & 7 & 5.5 & 128 & 100.0
\end{tabular}

Frequency Missing $=2$

INCREASE IN COMPOUNDED PRESCRIPTIONS

\begin{tabular}{|c|c|c|c|c|}
\hline EFA & Frequency & Percent & $\begin{array}{l}\text { Cumulative } \\
\text { Frequency }\end{array}$ & $\begin{array}{c}\text { Cumulative } \\
\text { Percent }\end{array}$ \\
\hline$-\cdots---1-1,-c-1$ & $-\cdots--\cdots--1$ & $-1-1$ & 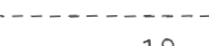 & $\cdots-1-\cdots$ \\
\hline $0-5 \%$ & 19 & 15.7 & 19 & 15.7 \\
\hline $6-10 \%$ & 10 & 8.3 & 29 & 24.0 \\
\hline $11-15$ 용 & 5 & 4.1 & 34 & 28.1 \\
\hline $16-20 \%$ & 2 & 1.7 & 36 & 29.8 \\
\hline REMAINED SAME & 22 & 18.2 & 58 & 47.9 \\
\hline DONT KNOW & 61 & 50.4 & 119 & 98.3 \\
\hline INCREASED & 2 & 1.7 & 121 & 100.0 \\
\hline
\end{tabular}

Frequency Missing $=9$ 
DECREASE IN COMPOUNDED PRESCRIPTIONS

\begin{tabular}{lcccc} 
& GHA & Frequency & $\begin{array}{c}\text { Cumulative } \\
\text { Percent }\end{array}$ & $\begin{array}{c}\text { Cumulative } \\
\text { Prequency }\end{array}$ \\
\hline $0-5 \%$ & 6 & 6.6 & 6 & 6.6 \\
$6-108$ & 1 & 1.1 & 7 & 7.7 \\
16-20\% & 2 & 2.2 & 9 & 9.9 \\
REMAINED SAME & 21 & 23.1 & 30 & 33.0 \\
DONT KNOW & 61 & 67.0 & 91 & 100.0 \\
& Frequency Missing $=39$ &
\end{tabular}

PERCENTAGE OF COMPOUNDED PRESCRIPTIONS IN TERMS OF TOTAL DOLLAR SALES

$\begin{array}{lrccc} & \text { IJA } & \text { Frequency } & \begin{array}{c}\text { Cumulative } \\ \text { Percent }\end{array} & \begin{array}{c}\text { Cumulative } \\ \text { Frequency }\end{array} \\ \text { Percent }\end{array}$

Frequency Missing $=5$

REQUIREMENT PHARMACIES TO COMPOUND PRESCRIPTIONS

\begin{tabular}{|c|c|c|c|c|c|}
\hline & KLA & Frequency & Percent & $\begin{array}{l}\text { Cumulative } \\
\text { Frequency }\end{array}$ & $\begin{array}{c}\text { Cumulative } \\
\text { Percent }\end{array}$ \\
\hline$\cdots \cdots$ & $-\cdots-$ & $---\cdots-\cdots$ & $-\cdots---$ & $-\cdots------$ & $---\cdots--$ \\
\hline YES IN & ALL & 45 & 34.6 & 45 & 34.6 \\
\hline YES IN & SOME & 2 & 1.5 & 47 & 36.2 \\
\hline NO & & 83 & 63.8 & 130 & 100.0 \\
\hline
\end{tabular}

REQUIRE PHARMACIES TO COMPOUND WITHIN REASONABLE TIME PERIOD

$\begin{array}{lrrrr} & \text { MNA } & \text { Frequency } & \begin{array}{c}\text { Cumulative } \begin{array}{c}\text { Cumulative } \\ \text { Percent }\end{array} \\ \text { Frequency }\end{array} \\ \text { YES IN 24H } & 28 & 21.5 & 28 & 21.5 \\ \text { YES MORE THAN 24 } & 5 & 3.8 & 33 & 25.4 \\ \text { NO } & 97 & 74.6 & 130 & 100.0\end{array}$




\section{BIBLIOGRAPHY}

Angelo, A.C. " Compounding is our heritage". U.S. Pharmacist. March 1992, 3.

Bloom, Marlene. "Compounding in Today's Practice". American Pharmacy. Oct. 1991 NS 31(10), 32.

Conlan, M.F. "Conterfeit Rx Drugs sends FDA Staff Prowling". Drug Topics. July $1992,67-68$.

Conlan, M.F. "Newest FDA Letters add to Compounding Confusion".

Drug Topics. Nov. 1992, 70-71.

Conlan, M.F. "New Compounding Guidelines dividing Pharmacy and FDA". Drug Topics. July 1992, 67-68

Crawford, S.Y. et al. "Extemporaneous Compounding Activities and the Associated Informational Needs of Patients". American Journal of Hospital Pharmacy. June 1991, 48: 1205-1210.

Conlan, M.F. "Compounding vs Manufacturing. Where is the line?" Drug Topics. June 1992, 15.

Martin, Sara. "APhA Secures Pharmacists Right to Compound". American Pharmacy. Nov. 1992 NS32(11), 26.

Myers, C.E. "Compounding for Human Use in the Future". Iournal of American Veterinary Medical Association. July 1994 205(2), 292-294.

O'Donnell, James. "Compounding the Problem". Drug Topics. Nov. 1992, 76-77.

Schwartz, Ronald. "Tuft War?" American Druggist. June 1992

Taddio, A. \& et al . "Bulk Compounding in Canadian Hospitals". The Canadian Iournal of Hospital Pharmacy, Oct. 1990 43(5), 213-218

Vivian, Jesse. "Compounding or Manufacturing?" U.S. Pharmacist. Oct. 1994, 112. 